\title{
Enhanced erosion performance of cold spray co-deposited AISI316 MMCs modified by friction stir processing
}

\author{
Tom Peat ${ }^{a}$, Alexander Galloway ${ }^{a}$, Athanasios Toumpis $^{\mathrm{a}}$, Russell Steel ${ }^{\mathrm{b}}$, Wenzhong Zhu ${ }^{\mathrm{c}}$, \\ Naveed lqbal ${ }^{d}$ \\ ${ }^{a}$ Department of Mechanical \& Aerospace Engineering, University of Strathclyde, James Weir \\ Building, 75 Montrose Street, Glasgow G1 1XJ, United Kingdom \\ ${ }^{\mathrm{b}}$ MegaStir Technologies, Provo, UT, 84058, USA \\ ${ }^{\mathrm{c}}$ School of Engineering and Computing, University of the West of Scotland, Paisley, \\ PA1 2BE, United Kingdom \\ ${ }^{\mathrm{d}}$ TWI Technology Centre, Wallis Way, Catcliff, Rotherham, S60 5TZ, United Kingdom
}

\begin{abstract}
The present study reports on the erosion properties of a novel surface engineering process combining cold spray and friction stir processing. Tungsten carbide (WC-CoCr) and aluminium oxide $\left(\mathrm{Al}_{2} \mathrm{O}_{3}\right)$ powders were cold spray co-deposited with AISI316 using a twin powder feed system. The deposited coatings were subsequently friction stir processed to refine and redistribute the reinforcing particles and remove the coating-to-substrate interface layer, thus generating a new metal matrix composite surface. Microstructural analysis of the SprayStirred (cold sprayed then friction stirred) specimens revealed significant particle refinement and improved particle distribution over the as-deposited coatings. The erosion performance of these SprayStirred surfaces was evaluated using a flowing slurry and demonstrated an $80 \%$ decrease in volume loss over the as-received AISI316 at $30^{\circ}$ angle of attack. For SprayStirred WC-CoCr, microhardness measurements indicated an increase of approx. $530 \%$ over the unaltered AISI316 and 100\% over the cold sprayed coating. These findings highlight the considerable increase in erosion performance of the SprayStirred specimens, and thus demonstrates the benefits of this innovative surface engineering process. This outcome is attributed to dispersion strengthening, imparted by the refined tungsten carbides. Furthermore, the SprayStirred WC-CoCr coating exhibited an $85 \%$ reduction in volume loss over an HVOF sprayed WC-CoCr coating.
\end{abstract}

\section{Keywords}

Friction stir processing; Cold spray; Metal matrix composite; Slurry erosion; $\mathrm{WC}-\mathrm{CoCr} ; \mathrm{Al}_{2} \mathrm{O}_{3}$

\section{Introduction}

Particle reinforced metal matrix composites (MMCs) have been shown to offer enhanced erosion properties over the bulk material. As such, the level of interest in these engineered materials has grown in recent years. Industries engaged in this research include automotive, mineral extraction and oil and gas, owing to the cost saving associated with producing wear resistant surfaces on cheaper substrate alloys. The present study examines a novel surface engineering technology combining cold gas dynamic spraying (cold spray) and friction stir 
processing, that has been optimised to successfully produce particle reinforced MMCs on the surface of AISI316.

Cold spray is a solid state coating technology that is used to produce coatings that retain the material properties of the feedstock powder. Coating deposition is achieved by accelerating the feedstock material to a supersonic velocity using a compressible carrier gas such as nitrogen or helium. The particles undergo extensive plastic deformation as they impact on the target surface which promotes bonding with the substrate material. The specific details relating to the bonding mechanisms are detailed elsewhere [1-3]. Cold spray offers several distinct advantages over high temperature coating processes including the prevention of oxidation [4], thermally induced phase changes [4,5], and tensile residual stresses [6]. Additionally, the cold spray process is capable of generating compressive residual stresses that enhance the fatigue performance of coatings over traditional thermal spray methods [7]. These key advantages are expanded upon in the published literature [8].

The deposition of erosion resistant feedstock powders such as cermets or oxides, has traditionally been difficult to achieve using the cold spray process. This is a result of the low ductility, and thus, limited plastic deformation of these erosion resistant powders, at the temperatures experienced during cold spray. Several research groups have attempted to overcome this limitation of the cold spray process by premixing ductile and cermet or oxide feedstock material [9] or by making use of agglomerated powders [10]. The drawbacks associated with premixing and using agglomerated powders are reviewed in the published literature [8].

In the present study, the difficulties in depositing erosion resistant coatings has been overcome using a novel co-deposition technique, whereby, the cermet or oxide powder (reinforcement) is co-deposited with a comparably ductile feedstock powder (binder), using a twin powder feed system. In this setup, two separate powder feeders supply the reinforcement and binder powders simultaneously to the cold spray nozzle, thus eliminating the need for premixing.

The strength of MMCs derives from the pinning of matrix dislocations by the reinforcing particles [11], with the amount of strengthening closely linked to the size, distribution and quantity of reinforcements within the matrix [12-15]. Microscale reinforcements impart strength through the load transfer from the soft, ductile matrix to the stiff reinforcements under an applied load [16]. The cold spray process imparts further strength to the binder particles in the form of work hardening [12] and grain refinement [16,17]. Severe plastic deformation of the binder produces an elongated grain structure, accompanied by an associated build up of dislocations resulting in work hardening [12]. Additionally, binder particles that directly impact the surface of the substrate, and hence experience particularly extensive plastic deformation, exhibit a finer grain structure when compared with the feedstock material. The high pressures that are generated when these particles impact the substrate cause the elongated grains to recrystallize $[17,18]$, thus producing the finer grain structure. Several investigations have evaluated the erosion and sliding wear properties of MMCs $[9,19,20]$ and report a substantial reduction in the erosion rate of particle reinforced MMCs over the uncoated substrate.

The cold spray process does, however, exhibit some notable drawbacks [21]. Often, the cold spray deposition of MMCs produces an inhomogeneous microstructure, with clustered reinforcements yielding areas of unreinforced matrix [22]. Furthermore, delamination can occur 
between coating and substrate, owing to lower adhesive strength as a result of the particles remaining below the solidus as they impact the surface of the substrate [23].

This investigation incorporates a novel two-stage surface engineering process referred to as SprayStir. The first stage involves the deposition of an MMC coating by cold spray. To mitigate the aforementioned disadvantages of the cold spray process, shallow penetration friction stir processing (FSP) is employed to modify the deposited coating and top surface of the substrate. The FSP process is detailed in prior studies [8,24,25].

Despite the reported improvements to the tribological and microstructural properties of different alloys by FSP $[26,27]$, the use of FSP on cold sprayed steel has not been extensively examined. However, one study by Morisada et al. [28] reported a 65\% increase in the hardness of a friction stir processed, HVOF deposited MMC over the as-deposited coating. The authors attributed this to the refinement and improved distribution of the tungsten and chromium carbides. Additionally, defects such as microcracking and porosity were eliminated post-FSP. Existing research concerning cold spray deposited MMCs is limited primarily to aluminium based MMCs [22,29]. Hodder et al. [22] investigated the effects of FSP on a cold spray deposited $\mathrm{MMC}$ containing $\mathrm{Al}_{2} \mathrm{O}_{3}$ particles. While the authors [22] highlighted the increased refinement and improved distribution of the oxides, they failed to examine the impact of these parameters on the erosion performance of the MMC. Huang et al. [29] investigated the effect of FSP on AA5056 reinforced with SiC particles. This group [29] carried out a microstructural examination of the post-FSP coating and reported significant refinement of the SiC particles. Moreover, their preliminary wear study revealed that the presence of the refined reinforcing particles increased the coefficient of friction over the as-received aluminium [29].

The present study advances the existing knowledge by examining the impact of FSP on cold spray co-deposited, steel based MMCs. The erosion performance of the MMC coatings (pre- and post-FSP) was evaluated under an impinging slurry at $90^{\circ}$ and $30^{\circ}$ angles of attack. The mass and volume loss of each specimen was measured, and the wear scar region inspected to identify the mechanisms that resulted in the removal of the coating.

\section{Methodology}

\subsection{Materials}

Tungsten carbide (WC-CoCr) and $\mathrm{Al}_{2} \mathrm{O}_{3}$ reinforced $\mathrm{MMC}$ coatings were deposited on stainless steel plates (AISI316). WC-CoCr is an agglomerated powder containing nano- and micro-scale tungsten carbides retained by a cobalt-chromium binder. The WC-CoCr particles are spherical and have an average diameter of $31 \mu \mathrm{m}$ (Fig.1a). Existing studies [30-32] demonstrate the superior erosion performance of this coating under dry and slurry testing [30].

In contrast, the $\mathrm{Al}_{2} \mathrm{O}_{3}$ particles contain no metallic binder and hence do not deform upon impact with the surface of the substrate. The faceted shape of the oxides is highlighted in Fig. 1b. The dissimilar size of the $\mathrm{WC}-\mathrm{CoCr}$ and $\mathrm{Al}_{2} \mathrm{O}_{3}$ particles employed in this study is due to the reported enhanced deposition efficiency and increased adhesive strength of larger grades of $\mathrm{Al}_{2} \mathrm{O}_{3}$ [33]. Like WC-CoC, $\mathrm{Al}_{2} \mathrm{O}_{3}$ reinforced $\mathrm{MMCs}$ have also been found to exhibit improved erosion properties [34].

Powders were deposited onto AISI316 as this alloy is commonly utilised in highly erosive working environments [35]. The co-deposited binder comprised AISI316 powder particles. This 
material was selected to ensure the stir zone would maintain the same chemical composition as the as-received AISI316 substrate alloy. The chemical composition of the powders and the substrate can be found in Table 1 and Table 2 respectively. The average particle size was measured using ImageJ analysis software.

Table 1. Powder composition [36-38]

\begin{tabular}{lll}
\hline $\begin{array}{l}\text { Coating } \\
\text { Material }\end{array}$ & Composition (wt.\%) & $\begin{array}{l}\text { Average Particle } \\
\text { Size }(\mu \mathrm{m})\end{array}$ \\
\hline WC-CoCr & $\mathrm{W}-10 \mathrm{Co}-5.5 \mathrm{C}-4.4 \mathrm{Cr}$ & 31 \\
$\mathrm{Al}_{2} \mathrm{O}_{3}$ & $100 \mathrm{Al}_{2} \mathrm{O}_{3}$ & 76 \\
$\mathrm{AISI} 316$ & $\mathrm{Fe}-17 \mathrm{Cr}-12 \mathrm{Ni}-12.5 \mathrm{Mo}$ & 20 \\
\hline
\end{tabular}

Table 2. Chemical composition of AISI316 substrate [39]

\begin{tabular}{ccccccccc}
\hline Element & $\mathrm{C}$ & $\mathrm{Mn}$ & $\mathrm{P}$ & $\mathrm{S}$ & $\mathrm{Si}$ & $\mathrm{Cr}$ & $\mathrm{Ni}$ & Mo \\
\hline wt.\% & 0.08 & 2 & 0.045 & 0.03 & 0.75 & $16-18$ & $10-14$ & $2-3$ \\
\hline${ }^{*}$ max values unless otherwise stated & & & & &
\end{tabular}

${ }^{*}$ max values unless otherwise stated

\subsection{Cold spray parameter development and deposition}

Cold spray co-deposition of the MMCs utilised a high pressure cold spray system (CGT Kinetiks 4000) connected to two powder feeders (Kinetiks PF 4000). The two powder feeders operated in parallel and supplied the binder and reinforcing particles simultaneously to the cold spray nozzle. A schematic diagram of the cold spray setup can be seen in Fig. 2.

An optimisation study was carried out to determine the powder feed rate that maximised the quantity of cermet/oxide particles deposited on the substrate. Three reinforcement loading ratios were examined $(30 \%, 60 \%$, and $90 \%)$, with subsequent image analysis revealing that $90 \%$ reinforcement to $10 \%$ binder resulted in the greatest quantity of reinforcing particles in the MMC.

A conventional de-Laval nozzle, using nitrogen as the carrier gas, was used to accelerate the powder particles to the necessary velocity. Prior work [40] identifies gas pressure, gas temperature and scanning speed as having the greatest influence on the quality (minimal porosity, large bonded surface area, cohesive strength) of the coating. Spraying parameters were optimised to yield a dense, well adhered coating, with the identified process parameters presented in Table 3 . The selected deposition ratio and optimised spraying parameters produced $0.38-0.44 \mathrm{~mm}$ thick coatings.

Table 3. Optimised cold spray deposition parameters

\begin{tabular}{llll}
\hline Gas & Gas Temperature & Scanning & Stand-off \\
$\begin{array}{l}\text { Pressure } \\
(\mathrm{MPa})\end{array}$ & $\left({ }^{\circ} \mathrm{C}\right)$ & Speed $(\mathrm{mm} / \mathrm{s})$ & Distance $(\mathrm{mm})$ \\
\hline
\end{tabular}




\begin{tabular}{|c|c|c|}
\hline 800 & 500 & 20 \\
\hline
\end{tabular}

\subsection{FSP parameter development and setup}

FSP of the cold sprayed plates was carried out using a TTI precision spindle friction stir welding/processing machine. In the present study, two tool configurations were utilised. The first, made of tungsten carbide and rhenium (W-Re), was used to process the uncoated AISI316 and $\mathrm{Al}_{2} \mathrm{O}_{3}$ coated plates. This tool featured a threaded $5 \mathrm{~mm}$ pin [41] and incorporated a concentric circular pattern on the shoulder. FSP of the WC-CoCr reinforced coating necessitated the use of a polycrystalline Boron Nitride ( $p c B N$ ) tool due to the excessive wear of the $\mathrm{W}-\mathrm{Re}$ tool when processing the $\mathrm{WC}-\mathrm{CoCr}$ coating. To maintain consistency in the investigation, the pcBN tool comprised similar features to the W-Re tool including a $5 \mathrm{~mm}$ threaded pin and concentric circular features on the shoulder. However, due to the design of the cooling system for the $\mathrm{pcBN}$ tool, no tilt angle was applied. Additionally, the pcBN tool rotated in an anti-clockwise direction. To prevent any movement of material during processing, the plates were secured to the tool bed using a mechanical clamping system.

FSP processing parameters were established for the uncoated AISI316 by examining the effect of tool traverse and rotational speed, and plunge depth on the stir zone. The outcome of the study highlighted plunge depth as having the greatest impact on the quality of the stir zone. The processing parameters that resulted in a good quality stir zone are offered in Table 4. For this study, the quality of the stir zone was based on the lack of surface voids and minimal flash [42].

Table 4. FSP parameters

\begin{tabular}{lllllll}
\hline Tool Type & $\begin{array}{l}\text { Pin } \\
\text { Length } \\
(\mathrm{mm})\end{array}$ & $\begin{array}{l}\text { Shoulder } \\
\text { Diameter } \\
(\mathrm{mm})\end{array}$ & $\begin{array}{l}\text { Rotational } \\
\text { Speed }(\mathrm{rpm})\end{array}$ & $\begin{array}{l}\text { Traverse } \\
\text { Speed } \\
(\mathrm{mm} / \mathrm{min})\end{array}$ & $\begin{array}{l}\text { Plunge } \\
\text { Depth } \\
(\mathrm{mm})\end{array}$ & $\begin{array}{l}\text { Tilt } \\
\text { Angle }\left({ }^{\mathrm{O}}\right)\end{array}$ \\
\hline W-Re & 5.7 & 18 & 250 & 100 & 5.9 & 2 \\
pcBN & 5.75 & 25.4 & 800 & 76 & N/A & 0 \\
\hline
\end{tabular}

\subsection{Evaluation methods}

\subsubsection{Microstructural characterisation}

A precision cutting wheel (Accutom 5) was used to cut transverse cross sections of the stir zone to examine the microstructure of the coatings pre- and post-FSP. Standard metallographic preparation techniques were used to prepare the sectioned specimens to a 0.5 $\mu \mathrm{m}$ finish. The various regions within the stir zone that are discussed throughout this work are displayed in Fig. 3.

Micrographs of the prepared surfaces were captured using an Olympus G51X light optical microscope. The ratio of matrix to reinforcements within the pre- and post-FSP specimens was measured at 500x magnification using image analysis software. Three micrographs were examined for each $\mathrm{MMC}$, to determine the average reinforcing particle 
content. The coating porosity was measured in accordance with the process outlined in ASTM E2109 - 01 [43]. High magnification electron micrographs of the MMCs depicting the distribution of carbides and oxides within the matrix were obtained using a scanning electron microscope (SEM), (Hitachi S-3700). Energy dispersive spectroscopy (EDS), using Oxford Instruments INCA software, was employed to map the positions of various elements within the MMC and highlighted the distribution of the reinforcing particles.

The average interparticle spacing between the reinforcing particles was established preand post-FSP using a statistical analysis approach developed by Khare \& Burris [44]. This method [44] calculates the free-space length between neighbouring particles. This is achieved by randomly placing squares of progressively smaller width, until the average number of intersecting reinforcing particles is zero. In the present study, the number of random squares placed on the images was 10,000 .

\subsubsection{Microhardness and nanoindentation analysis}

The microhardness of the SprayStirred and as-deposited MMCs was measured using a Mitutoyo MVK-G1 microhardness tester with a 4-sided diamond indenter. Indents were made using an applied load of $200 \mathrm{gf}$ at several locations across the width of the stir zone (Fig. 3). The results were analysed to determine the influence of FSP on the average hardness, as well as identify the average hardness in the different stir zone regions (Fig. 3).

The nanoindentation analysis was carried out using the Agilent Nano Indenter G200. The measurement involves continuously monitoring the load and displacement (i.e. depth of indentation into the surface of the specimen) of an indenter during an indentation load-unload cycle. A Berkovich indenter [45] was used for this study. To establish the hardness of the specimen, the maximum load is divided by the contact area, which corresponds to the depth of the indentation. This approach was first developed by Oliver and Pharr and is discussed in detail elsewhere $[45,46]$. A total of 100 Indentations were made at $10 \mu \mathrm{m}$ intervals, covering a total surface area of $100 \mu \mathrm{m}^{2}$. The nanoindentation results were converted from GPa to $\mathrm{HV}$ using the conversion factor stated in ASTM E92 - 16 [47], to enable a direct comparison with microhardness.

\subsubsection{Slurry erosion testing}

Slurry erosion testing was carried out using a recirculating slurry solution comprising $3.5 \% \mathrm{NaCl}$ solution and FS9 grade angular silica ( $\mathrm{SiC}$ ) particles with an average size of $0.4 \mathrm{~mm}$. A detailed description and schematic of the test apparatus is reported elsewhere [8]. This design of test rig has been used extensively by researchers examining the erosion performance of materials under flowing conditions [30,48,49]. Flow velocity, sand content and standoff distance have all been shown to directly affect the level of erosion experienced by specimens exposed to slurry testing [50,51]. A recirculating system enables accurate control over these variables, thereby ensuring consistent testing conditions.

Test coupons were sectioned from the cold sprayed and SprayStirred plates using water-jet cutting equipment. Any surface roughness was removed with 500-grit SiC paper. Test coupons were secured directly beneath the jet nozzle and fully submerged in the slurry solution. Specimen holders positioned at $30^{\circ}$ and $90^{\circ}$ to the slurry facilitated the assessment of different angles of attack. Test coupons were weighed pre- and post-testing to establish to total mass 
loss. The rig was flushed with fresh water following each test to remove any trace of SiC particles. The mass loss from an AISI316 control specimen was measured prior to the assessment of the MMCs to ensure constant erosive conditions. The specific test parameters for the erosion study can be found in Table 5 .

Table 5. Solid liquid impingement test parameters.

\begin{tabular}{lllll}
\hline $\begin{array}{l}\text { Flow Velocity } \\
(\mathrm{m} / \mathrm{s})\end{array}$ & $\begin{array}{l}\text { Sand } \\
\text { Concentration } \\
(\mathrm{g} / \mathrm{l})\end{array}$ & $\begin{array}{l}\text { Standoff } \\
\text { Distance }(\mathrm{mm})\end{array}$ & $\begin{array}{l}\text { Test Time } \\
(\mathrm{min})\end{array}$ & $\begin{array}{l}\text { Sample } \\
\text { Dimensions } \\
(\mathrm{mm})\end{array}$ \\
\hline 18 & 1 & 5 & 60 & $20 \times 20$ \\
\hline
\end{tabular}

A focal variation microscope (Alicona Infinite Focus G4) [52] was used to establish the volume of the wear scars generated by the impinging slurry. The system [52] constructs a 3D model by layering multiple images of the wear scar region at different focal lengths. This model contains numerous data points that are measured in relation to a reference plane that represents the original top surface of the specimen. The volume of the wear scar was calculated by measuring the distance between the data points and the reference plane.

\section{Results and Discussion}

\subsection{MMC coating characterisation}

\subsubsection{Light optical microscopy}

Fig. 4 depicts the approx. location within the as-deposited and SprayStirred MMCs from which the micrographs in Fig. 5 were taken. Fig. $4 a$ exhibits the microstructure of the asdeposited WC-CoCr MMC in which no cracking is observed. More importantly, Fig 4a does illustrate the abrupt interface between the cold sprayed coating and the substrate, a typical cause of delamination [53]. In the SprayStirred condition (Fig. 4b), there is a gradual transition from the coating into the surface, with the coating now an intrinsic part of the bulk material. The indicated porosity was found to be less than $0.5 \%$, and thus was considered zero in accordance with ASTM E2109 - 01 [43]. The absence of any defects is attributed to the significant plastic deformation of the AISI316 binder particles as they impact on the surface of the substrate. The absence of defects in the coating is due to the ductility of the binder at the point of contact; this binder deforms around the carbides and oxides resulting in minimal porosity.

Agglomerates of $\mathrm{WC}-\mathrm{CoCr}$ particles are present in the as-deposited MMC. This inhomogeneous distribution of reinforcements produces regions that contain high concentrations of carbides and regions that contain no reinforcements. Thus, the material properties of the MMC are not uniform throughout the coating. Image analysis calculated that the coating contains approx. $60 \%$ reinforcements to $40 \%$ matrix. This value is less than the $90 \%$ ratio that was supplied to the nozzle by the powder feeder due to the comparably ductile AISI316 experiencing greater deformation than the WC-CoCr cermet. At the point of impact, the limited ductility of the WC-CoCr particles causes some to rebound from the surface, resulting in a lower quantity within the MMC. 
Fig. 5 presents the microstructure of the as-deposited and SprayStirred WC-CoCr coatings and highlights the variation in the microstructure pre- and post-FSP. Fig. 5a exhibits the as-deposited microstructure of the $\mathrm{WC}-\mathrm{CoCr}$ reinforced $\mathrm{MMC}$, while Fig. $5 \mathrm{~b}$ shows the significant dispersal of the WC-CoCr agglomerates observed in the as-deposited condition (Fig. 5a). This dispersal is limited to the top surface of the stir zone, with the larger as-deposited agglomerates located further from the surface. The variable microstructure through the depth of the stir zone is related to the increased plasticity at the surface of the stir zone and occurs with close proximity to the shoulder of the tool where the frictional heat is highest.

The refinement of the agglomerates on the top surface is associated with the shear force that is exerted by the shoulder as it stirs the plasticised material [54,55]. During FSP, this shearing by the rotating tool deforms the agglomerates beyond the elastic limit of the Co-Cr binder and AISI316 resulting in the dispersal of the individual carbides throughout the matrix. The deformation of the WC-CoCr agglomerates is demonstrated in Fig. 6.

The microstructures of the as-deposited and SprayStirred $\mathrm{Al}_{2} \mathrm{O}_{3}$ reinforced $\mathrm{MMC}$ are exhibited in Fig. 7, with Fig. 7a showing illustrating the microstructure of the as-deposited coating, and Fig. $7 \mathrm{~b}$ revealing the SprayStirred microstructure. Fig. 7b demonstrates significant refinement of the as-deposited oxides (compared to Fig. 7a). During FSP, the shear force exerted by the tool fractured the large particles and distributed them throughout the plasticised AISI316 matrix. Consequently, this has produced a homogeneous distribution of the reinforcing particles when compared to the as-deposited coating. As was observed in the $\mathrm{WC}-\mathrm{CoCr}$ reinforced $M M C$, the level of particle refinement in the SprayStirred $\mathrm{Al}_{2} \mathrm{O}_{3}$ is greater towards the top surface of the stir zone.

\subsubsection{Scanning electron microscopy}

EDS was employed to generate maps that depict the position of specific elements within the MMC. By highlighting the various elements within the $\mathrm{MMC}$, the distribution of the reinforcing particles can be observed and hence, the level of refinement achieved by FSP can be clearly exhibited. The particle distribution before and after FSP for the $\mathrm{Al}_{2} \mathrm{O}_{3}$ reinforced MMC is exhibited in Fig. 8 and shows that FSP has successfully improved the dispersion of the reinforcing particles and caused substantial refinement of the as-deposited oxide particles. EDS software calculated the wt.\% of the various elements within the MMC coating, with the results offered in Table 6.

Table 6. EDS elemental analysis (wt.\%)

\begin{tabular}{lcccccccccc}
\hline & & $\mathrm{Mn}$ & $\mathrm{Al}$ & $\mathrm{Cr}$ & $\mathrm{Ni}$ & $\mathrm{Co}$ & $\mathrm{W}$ & $\mathrm{Fe}$ & $\mathrm{O}$ & Mo \\
\hline \multirow{2}{*}{ As-Deposited } & $\mathrm{WC}-\mathrm{CoCr}$ & 0.62 & & 10.46 & 4.73 & 4.91 & 49.63 & 28.60 & & \\
& $\mathrm{Al}_{2} \mathrm{O}_{3}$ & & 10.56 & 14.72 & 9.80 & & & 54.01 & 7.12 & 2.51 \\
\hline SprayStirred & $\mathrm{WC}-\mathrm{CoCr}$ & 0.77 & & 9.71 & 5.01 & 5.92 & 51.27 & 27.32 & & \\
(Retreating) & $\mathrm{Al}_{2} \mathrm{O}_{3}$ & 1.12 & 6.56 & 16.06 & 10.03 & & & 58.47 & 5.23 & 2.53 \\
\hline SprayStirred & $\mathrm{WC}-\mathrm{CoCr}$ & 0.57 & & 10.16 & 5.08 & 5.46 & 50.24 & 28.49 & & \\
(Advancing) & $\mathrm{Al}_{2} \mathrm{O}_{3}$ & 1.33 & 9.18 & 15.71 & 10.22 & & & 56.02 & 5.52 & 2.02 \\
\hline
\end{tabular}


Image analysis established that equivalent quantities of reinforcements were present in the as-deposited and SprayStirred MMCs. This outcome confirms that the reinforcing particles are redistributed during FSP, as opposed to being removed. Similar wt.\% of reinforcing particles were measured in the retreating and advancing sides of the stir zone, thus demonstrating that the carbide/oxide reinforcements have been evenly distributed across the top surface of the stir zone.

\section{$\underline{3.1 .3 ~ M i c r o h a r d n e s s ~}$}

The broad scatter of microhardness results (Fig. 9) is related to the specific locations (Fig. 3) on which the indents were produced and the highly dissimilar hardness of the reinforcements and AISI316 matrix. Indents on regions with increased carbide density, i.e. the agglomerates, yield a high hardness, due to the greater hardness of the carbides. Correspondingly, areas void of reinforcements exhibit a comparably low hardness.

For the as-received AISI316 (no coating), FSP has increased the average hardness within the stir zone by approx. $20 \%$. This finding is widely reported in existing literature $[26,56]$ and is attributed to the grain refinement generated by FSP.

The SprayStirred WC-CoCr specimen demonstrated a significant hardness increase $(500 \%)$ over the as-received AISI316 in the centre of the stir zone. This location correlates to the region (Fig. 3) that has experienced the greatest level of particle refinement. Thus, the result is in agreement with previous work which attributes hardening to the presence of evenly dispersed nanoscale carbides [15]. Furthermore, the SprayStirred WC-CoCr coating was found to be approx. $100 \%$ harder than the as-deposited WC-CoCr MMC, thereby highlighting the benefits of the SprayStir process over cold spray alone.

The SprayStirred $\mathrm{Al}_{2} \mathrm{O}_{3}$ exhibits a $50 \%$ increase in hardness over the as-received AISI316. This increase is a consequence of the matrix grain refinement, as discussed above, and the presence of homogeneously distributed reinforcing particles within the sir zone. However, this value corresponds to a $25 \%$ reduction in hardness when compared to the cold sprayed $\mathrm{Al}_{2} \mathrm{O}_{3}$ coating (without FSP). This finding is a consequence of the inhomogeneous distribution of reinforcing particles in the cold sprayed coating, that yields greater spacing between neighbouring $\mathrm{Al}_{2} \mathrm{O}_{3}$ reinforcements, thereby resulting in greater variability in the microhardness measurements.

\subsubsection{Nanoindentation study}

Optical micrographs depicting the nanoindentation impressions on the cross sectioned surface of the as-deposited and SprayStirred MMCs can be seen in Fig. 10. EDS analysis has confirmed that the dark-shaded regions correspond to the reinforcing particles and the lightshaded areas represent the AISI316 matrix. Fig. 11a and Fig 11b exhibit hardness maps of the indented regions on the as-deposited and SprayStirred specimens respectively.

The high and low hardness values, shown in Fig 11 correlate to the locations of reinforcing particles depicted in the micrograph (Fig. 10). The hardness map of the SprayStirred surface highlights a more uniform hardness distribution throughout the examined region, thereby demonstrating the homogenising effect of FSP. For example, the maximum recorded hardness of the WC-CoCr MMC was found to be in the range of 3000-3500 HV and was located at point g11. Post-FSP, there are no high hardness peaks. Instead, the WC-CoCr agglomerates on which these high values were measured have been redistributed throughout the MMC. 
The nanoindentation analysis also indicates a greater hardness value than was measured during the microhardness analysis. In the latter, the load applied to the surface of the specimen created an indent several microns deep. Given that the size of this indent is greater than the reinforcement size, the measurement represents the average hardness of the reinforcement and the surrounding matrix. In nanoindentation, the impressions have a max depth of approx. $300 \mathrm{~nm}$, therefore the limitations associated with microhardness assessment are avoided. Hence, the nanohardness examination offers a more precise indication of the hardness at specific regions within the MMCs.

\subsubsection{Interparticle spacing}

Prior research [12,15] correlates the increased hardness of the MMC to improved homogeneity in particle distribution. Moreover, the studies highlight enhanced hardness with decreasing particle spacing (interparticle spacing) [15]. A statistical method developed by Khare \& Burris [44] was employed to evaluate the distribution of reinforcements in the current study. In this method, particle agglomerates are accounted for as it is the free-space of the matrix, rather than the number of particles that is measured. The results are presented in Table 7.

Table 7. Interparticle distance

\begin{tabular}{lll}
\hline Coating & WC-CoCr & $\mathrm{Al}_{2} \mathrm{O}_{3}$ \\
\hline $\begin{array}{l}\text { Interparticle distance }(\mu \mathrm{m}) \\
\text { (as-deposited) }\end{array}$ & 15.3 & 22.6 \\
\hline $\begin{array}{l}\text { Interparticle distance }(\mu \mathrm{m}) \\
\text { (SprayStirred) }\end{array}$ & 1.4 & 2.6 \\
\hline $\begin{array}{l}\text { Reduction in interparticle } \\
\text { distance }(\%)\end{array}$ & 91 & 88 \\
\hline
\end{tabular}

In the as-deposited condition, the WC-CoCr reinforcements exhibit smaller interparticle spacing than was measured between the as-deposited $\mathrm{Al}_{2} \mathrm{O}_{3}$ particles. This outcome is primarily attributed to the lower oxide content within the MMC (Section 3.1.1). Furthermore, the structure of the WC-CoCr particles allows for slight deformation upon contact with the surface. This deformation enables the carbides to coalesce with surrounding particles and hence contributes to the lower interparticle spacing of the WC-CoCr reinforcements.

The WC-CoCr cermet is comprised of nanoscale carbides retained by a CoCr binder. Therefore, it is not necessary for FSP to refine any of the carbides. Instead, FSP must deform the WC-CoCr agglomerate beyond its elastic limit, thereby allowing the carbides to be distributed throughout the plasticised AISI316 matrix. This requires less energy than what would be necessary to fracture particles and, therefore, accounts for the significant drop in the interparticle spacing in the WC-CoCr MMC.

SprayStirred $\mathrm{Al}_{2} \mathrm{O}_{3}$ demonstrates a marginally smaller reduction in interparticle distance of $88 \%$. The decrease in the level of refinement experienced by the $\mathrm{Al}_{2} \mathrm{O}_{3}$ particles, as compared with the $\mathrm{WC}-\mathrm{CoCr} \mathrm{MMC}$, is primarily ascribed to the morphology of the oxide 
particles. Unlike the $\mathrm{WC}-\mathrm{CoCr}$, the $\mathrm{Al}_{2} \mathrm{O}_{3}$ reinforcements are solid particles without any inherent ductile binder and hence, require more energy to fracture and redistribute.

\subsection{Slurry erosion study}

\subsubsection{Mass loss}

The pre- and post-FSP mass loss for the two MMCs and the AISI316 is presented in Fig. 12. The influence of FSP on the mass loss has been measured following impingement at $90^{\circ}$ and $30^{\circ}$ and is shown in Fig. $12 \mathrm{a}$ and Fig $12 \mathrm{~b}$ respectively. Due to the dissimilar densities of the WC-CoCr and $\mathrm{Al}_{2} \mathrm{O}_{3}$ reinforcements, the mass loss cannot be used to compare the two MMCs and the AISI316. However, the measurements do provide an indication as to the relative erosion performance of each coating under $90^{\circ}$ and $30^{\circ}$ angle of attack.

For both MMCs, the SprayStirred specimen has exhibited a reduction in mass loss over the as-deposited coating and the as-received AISI316. In the case of the uncoated AISI316, the improved erosion performance measured in the friction stir processed specimen is accredited to the grain refinement generated by FSP and the corresponding hardness increase [56].

Examination of the mass loss highlights superior erosion resistance of the SprayStirred MMC as compared to the corresponding cold sprayed coating. This improvement is related to the homogeneous distribution of the reinforcements throughout the MMC. This distribution reduces the surface area of unreinforced material that is exposed to the impinging slurry and also increases the hardness of the matrix through dispersion strengthening [12]. The harder matrix is more resistant to erosion at shallow angles of attack, owing to the specific erosion mechanisms operating at shallow and steep angles of impingement [57]. These mechanisms will be discussed in detail in Section 3.2.3.

\subsubsection{Volume loss}

To directly compare the erosion performance of the different specimens, the volume of the wear scar produced by the erosive slurry was measured for each specimen at $90^{\circ}$ (Fig. 13a) and $30^{\circ}$ (Fig 13b) impingement.

Post-FSP, the uncoated specimens experienced a significant reduction (45\%) in volume loss under $30^{\circ}$ angle of attack (Fig. 13b). However, at $90^{\circ}$ impingement (Fig. 13a), post-FSP AISI316 only exhibited a $6 \%$ drop in volume loss. This outcome is a consequence of the grain refinement within the stir zone and corresponding hardness increase (Fig. 9). Aquaro et al. [58] report improved erosion resistance of harder alloys at shallow angles of attack due to the harder alloy being more resistant to the ploughing and cutting damage operating at such angles.

In the SprayStirred condition, the WC-CoCr reinforced MMC has yielded a $52 \%$ and $70 \%$ reduction in volume loss at $90^{\circ}$ and $30^{\circ}$ impingement, over the post-FSP AISI316. This outcome represents a significant improvement to the erosion performance of the AISI316 following the application of the SprayStir process. Additionally, a $77 \%$ and $67 \%$ reduction in the volume loss has been recorded for the SprayStirred WC-CoCr MMC, over the as-deposited WC-CoCr. This outcome demonstrates the beneficial impact of FSP on the erosion performance of the engineered surface and confirms the significant influence of particle distribution on the subsequent erosion performance. Furthermore, the SprayStirred WC-CoCr has exhibited superior erosion performance to an HVOF deposited $\mathrm{WC}-\mathrm{CoCr}$ coating under similar testing 
conditions [59]. The SprayStirred coating exhibits an $85 \%$ reduction in volume loss over the values reported by Peat et al. [59].

Under $90^{\circ}$ impingement (Fig. 13a), the SprayStirred $\mathrm{Al}_{2} \mathrm{O}_{3}$ reinforced $M M C$ offers no measurable improvement to the erosion performance over the as-received AISI316. However, at $30^{\circ}$ the SprayStirred $\mathrm{Al}_{2} \mathrm{O}_{3}$ measures a $36 \%$ drop in the volume loss. At shallow angles of attack, the impinging particles cut and plough the soft matrix alloy [57,60]. Conversely, at high impact angles, the process of material removal begins with the formation of impact craters on the surface of the impinged region. The SprayStirred $\mathrm{Al}_{2} \mathrm{O}_{3}$ has provided greater erosion resistance at $30^{\circ}$ impingement due to the refined oxides limiting the depth of the cutting and ploughing produced by the $\mathrm{SiC}$ particles. The fracture and pull out of the oxides under $90^{\circ}$ impingement has resulted in no change to the volume loss. Despite the significant refinement of the $\mathrm{Al}_{2} \mathrm{O}_{3}$ oxides, the particles are still larger than the tungsten carbides (Table 1). Consequently, the superior erosion performance of the SprayStirred WC-CoCr MMC aligns with a greater quantity of reinforcements, smaller particle size and reduced interparticle spacing.

\section{$\underline{3.2 .3 \text { Wear scar analysis }}$}

To elucidate the findings of the volume loss analysis, micrographs of the impinged region were examined to identify the mechanisms resulting in the removal of material. Fig. 14 presents the macroscopic images of the examined wear scar surfaces. Fig. 15 depicts the different erosion mechanisms operating on the surface of the uncoated AISI316 for each angle of attack. At $90^{\circ}$ (Fig. 15a), the damage on the surface of the specimen is dominated by the production of impact craters and corresponding thinned material on the periphery of these craters [58]. Subsequent strikes remove the weakened AISI316 located on the edge of the craters through a low cycle fatigue process. At $30^{\circ}$ impingement, material removal occurs through the cutting of the soft AISI316 matrix. These findings align with the reported erosion mechanisms of ductile alloys [57].

Fig. 16a depicts the erosive damage on the as-deposited WC-CoCr coating at $30^{\circ}$ angle of attack. The image reveals evidence of cutting and ploughing similar to that observed on the unreinforced AISI316. However, the level of plastic deformation on the specimen surface is noticeably less, thus highlighting the beneficial impact of the WC-CoCr. However, at $90^{\circ}$ erosion is dominated by cracking and pull out of the carbides from the matrix. Repeated SiC impacts cause cracking within the WC-CoCr agglomerates. As the cracks grow and intersect with the matrix, the WC-CoCr agglomerates are loosened and are eventually dislodged from the MMC leaving a void.

The damage to the SprayStirred WC-CoCr MMC at $30^{\circ}$ impingement can be seen in Fig. 16b. The ploughing observed in the as-deposited coating (Fig. 15b) does not exist on the surface of the SprayStirred WC-CoCr MMC (Fig. 16b). When the size of the eroding particles is substantially greater than the refined reinforcements, the carbides are incapable of deflecting the impinging particles. Instead, the carbides increase the hardness of the matrix through dispersion strengthening [12]. This subsequently reduces the depth of the surface damage, thus, decreasing the volume of the wear scar. Similar erosion mechanisms have been reported in existing literature [30,31]. Additionally, uniform distribution of the reinforcing particles reduces the surface area of the unreinforced matrix that was exposed to the slurry solution, thus reducing the damage on the surface of the specimen. 
Fig. 17 highlights the damage to the as-deposited (Fig 17a) and SprayStirred (Fig 17b) $\mathrm{Al}_{2} \mathrm{O}_{3}$ reinforced $\mathrm{MMCs}$ following impact at $30^{\circ}$. The micrographs (Fig.17) illustrate similar damage to the uncoated AISI316, specifically exhibiting signs of ploughing and cutting. While the oxides are capable of the deflecting the impinging $\mathrm{SiC}$ particles, $\mathrm{Al}_{2} \mathrm{O}_{3}$ is not present in sufficient quantities to enhance the erosion performance of the coating.

The reduced volume loss measured on the SprayStirred $\mathrm{Al}_{2} \mathrm{O}_{3}$ specimen is attributed to the homogeneous distribution of the refined oxide particles imparting hardening through dispersion strengthening [15]; thereby making the surface more resistant to ploughing and cutting by the $\mathrm{SiC}$ particles. While not as effective as the $\mathrm{WC}-\mathrm{CoCr}$ reinforced $\mathrm{MMC}$, the SprayStirred $\mathrm{Al}_{2} \mathrm{O}_{3}$ offers improved erosion performance over the as-received and post-FSP AISI316

\section{Conclusions}

This study evaluated SprayStir as a surface engineering processes for producing highly erosion resistant particle reinforced MMCs on AISI316 substrate. WC-CoCr and $\mathrm{Al}_{2} \mathrm{O}_{3}$ feedstock powder particles were successfully co-deposited with AISI316 binder particles to produce particle reinforced MMC coatings. The coatings have subsequently been modified using FSP to refine and redistribute the reinforcing particles. Based on the findings of this investigation, the following conclusions can be drawn:

- The substantial plastic deformation generated by FSP has resulted in the dispersion of the as-deposited $\mathrm{WC}-\mathrm{CoCr}$ agglomerates and refinement of the $\mathrm{Al}_{2} \mathrm{O}_{3}$ particles. Moreover, examination of optical and scanning electron micrographs reveal an even distribution of reinforcements across the top surface of the stir zone.

- The average microhardness of the SprayStirred WC-CoCr was $1120 \mathrm{HV}$. This result correlates to a $50 \%$ increase over the cold sprayed coating and a $500 \%$ increase over the as-received AISI316. This increase has been achieved through dispersion strengthening imparted into the matrix by the nanoscale carbide reinforcements.

- Nanoindentation shows a significant reduction in the range of the measured hardness values in the SprayStirred condition. Therefore, the SprayStir process has improved the hardness homogeneity, thereby generating uniform mechanical properties throughout the MMC. This homogenising effect was exhibited in both the $\mathrm{WC}-\mathrm{CoCr}$ and $\mathrm{Al}_{2} \mathrm{O}_{3}$ reinforced MMCs.

- The interparticle spacing measurements demonstrate a $91 \%$ and $88 \%$ reduction in the spacing of the WC-CoCr and $\mathrm{Al}_{2} \mathrm{O}_{3}$ reinforced MMCs post-FSP. In both cases, FSP has successfully refined the as-deposited particles and distributed them throughout the MMC.

- At $90^{\circ}$, erosion was dominated by the removal of weakened material on the periphery of impact craters. The presence of the carbide/oxide reinforcements reduces the depth of the craters owing to their increased hardness, while the small size of the particles prevents them from being easily dislodged from the matrix. 
- At $30^{\circ}$, the refined reinforcements limit the depth of the surface damage by imparting dispersion strengthening into the MMC. Additionally, the homogeneous distribution of carbide/oxides reduces the surface area of unreinforced AISI316 exposed to the slurry.

- The WC-CoCr reinforced MMC demonstrated an $80 \%$ decrease in volume loss over the as-received AISI316 at $30^{\circ}$ angle of attack. Additionally, the SprayStirred WC-CoCr exhibited a $75 \%$ reduction in volume loss over the as-deposited coating. The improved erosion performance is directly related to the reduction in interparticle spacing and matrix hardening through dispersion strengthening.

\section{References}

[1] A. Papyrin, V. Kosarev, S. Klinkov, A. Alkhimov, V. Fomin, Cold Spray Technology, Elsevier, 2006.

[2] V.K. Champagne, The cold spray materials deposition process: fundamentals and applications, Woodhead Publishing, 2007.

[3] H. Assadi, F. Gärtner, T. Stoltenhoff, H. Kreye, Bonding mechanism in cold gas spraying, Acta Mater. 51 (2003) 4379-4394.

[4] D. Toma, W. Brandl, G. Marginean, Wear and corrosion behaviour of thermally sprayed cermet coatings, Surf. Coat. Technol. (2001) 149-158.

[5] D.K. Goyal, H. Singh, H. Kumar, V. Sahni, Slurry erosion behaviour of HVOF sprayed WC-10Co-4Cr and Al $2 \mathrm{O}$ 3+13TiO 2 coatings on a turbine steel, Wear. 289 (2012) 4657.

[6] U. Selvadurai, P. Hollingsworth, I. Baumann, B. Hussong, W. Tillmann, S. Rausch, et al., Influence of the handling parameters on residual stresses of HVOF-sprayed WC-12Co coatings, Surf. Coatings Technol. 268 (2014) 30-35.

[7] G. Shayegan, H. Mahmoudi, R. Ghelichi, J. Villafuerte, J. Wang, M. Guagliano, et al., Residual stress induced by cold spray coating of magnesium AZ31B extrusion, Mater. Des. 60 (2014) 72-84.

[8] T. Peat, A. Galloway, A. Toumpis, P. McNutt, N. Iqbal, The erosion performance of cold spray deposited metal matrix composite coatings with subsequent friction stir processing, Appl. Surf. Sci. (2016).

[9] X. Luo, C. Li, Large sized cubic BN reinforced nanocomposite with improved abrasive wear resistance deposited by cold spray, Mater. Des. 83 (2015) 249-256.

[10] S. Dosta, G. Bolelli, A. Candeli, L. Lusvarghi, I. Garcia, J. Maria, Plastic deformation phenomena during cold spray impact of WC-Co particles onto metal substrates, Acta Mater. 124 (2017) 173-181.

[11] Z. Zhang, D.L. Chen, Contribution of Orowan strengthening effect in particulatereinforced metal matrix nanocomposites, Mater. Sci. Eng. A. 483-484 (2008) 148-152.

[12] X.T. Luo, G.J. Yang, C.J. Li, Multiple strengthening mechanisms of cold-sprayed cBNp/NiCrAl composite coating, Surf. Coatings Technol. 205 (2011) 4808-4813.

[13] H. Gül, F. Kili, M. Uysal, S. Aslan, A. Alp, H. Akbulut, Effect of particle concentration on the structure and tribological properties of submicron particle SiC reinforced Ni metal matrix composite (MMC) coatings produced by electrodeposition, Appl. Surf. Sci. 258 (2012) 4260-4267.

[14] D.A. Stewart, P.H. Shipway, D.G. McCartney, Abrasive wear behaviour of conventional and nanocomposite HVOF-sprayed WC-Co coatings, Wear. 225-229 (1999) 789-798.

[15] A.M. Redsten, E.M. Klier, A.M. Brown, D.C. Dunand, Mechanical properties and microstructure of cast oxide-dispersion-strengthened aluminum, Mater. Sci. Eng. A. 201 (1995) 88-102. 
[16] B. Chen, S. Li, H. Imai, L. Jia, J. Umeda, M. Takahashi, Load transfer strengthening in carbon nanotubes reinforced metal matrix composites via in-situ tensile tests, Compos. Sci. Technol. 113 (2015) 1-8.

[17] W. Li, K. Yang, D. Zhang, X. Zhou, X. Guo, Interface behavior of particles upon impacting during cold spraying of Cu/Ni/Al mixture, Mater. Des. 95 (2016) 237-246.

[18] A.C. Hall, L.N. Brewer, T.J. Roemer, Preparation of aluminum coatings containing homogenous nanocrystalline microstructures using the cold spray process, J. Therm. Spray Technol. 17 (2008) 352-359.

[19] A. Rokanopoulou, P. Skarvelis, G.D. Papadimitriou, Improvement of the tribological properties of $\mathrm{Al} 2 \mathrm{O} 3$ reinforced duplex stainless steel MMC coating by the addition of TiS2 powder, Surf. Coat. Technol. 289 (2016) 144-149.

[20] M. Moazami-goudarzi, F. Akhlaghi, Wear behavior of Al 5252 alloy reinforced with micrometric and nanometric SiC particles, Tribiology Int. 102 (2016) 28-37.

[21] H.X. Hu, S.L. Jiang, Y.S. Tao, T.Y. Xiong, Y.G. Zheng, Cavitation erosion and jet impingement erosion mechanism of cold sprayed Ni-Al2O3 coating, Nucl. Eng. Des. 241 (2011) 4929-4937.

[22] K.J. Hodder, H. Izadi, A.G. McDonald, A.P. Gerlich, Fabrication of aluminum-alumina metal matrix composites via cold gas dynamic spraying at low pressure followed by friction stir processing, Mater. Sci. Eng. A. 556 (2012) 114-121.

[23] R. Ghelichi, D. MacDonald, S. Bagherifard, H. Jahed, M. Guagliano, B. Jodoin, Microstructure and fatigue behavior of cold spray coated Al5052, Acta Mater. 60 (2012) 6555-6561.

[24] A. Rahbar-kelishami, A. Abdollah-zadeh, M.M. Hadavi, A. Banerji, A. Alpas, A.P. Gerlich, Effects of friction stir processing on wear properties of WC - 12\% Co sprayed on 52100 steel, Mater. Des. 86 (2015) 98-104.

[25] O.S. Salih, H. Ou, W. Sun, D.G. Mccartney, A review of friction stir welding of aluminium matrix composites, Mater. Des. 86 (2015) 61-71.

[26] H.S. Arora, H. Singh, B.K. Dhindaw, Wear behaviour of a Mg alloy subjected to friction stir processing, Wear. 303 (2013) 65-77.

[27] C. Lorenzo-Martin, O.O. Ajayi, Rapid surface hardening and enhanced tribological performance of 4140 steel by friction stir processing, Wear. 332-333 (2015) 962-970.

[28] Y. Morisada, H. Fujii, T. Mizuno, G. Abe, T. Nagaoka, M. Fukusumi, Modification of thermally sprayed cemented carbide layer by friction stir processing, Surf. Coatings Technol. 204 (2010) 2459-2464.

[29] C. Huang, W. Li, Z. Zhang, M. Fu, M. Planche, H. Liao, et al., Modification of a cold sprayed SiCp/Al5056 composite coating by friction stir processing, Surf. Coatings Technol. 296 (2016) 69-75.

[30] A. Neville, F. Reza, S. Chiovelli, T. Revega, Erosion-corrosion behaviour of WC-based MMCs in liquid-solid slurries, Wear. 259 (2005) 181-195.

[31] L. Thakur, N. Arora, R. Jayaganthan, R. Sood, An investigation on erosion behavior of HVOF sprayed WC-CoCr coatings, Appl. Surf. Sci. 258 (2011) 1225-1234.

[32] L. Thakur, N. Arora, A comparative study on slurry and dry erosion behaviour of HVOF sprayed WC-CoCr coatings, Wear. 303 (2013) 405-411.

[33] H.Y. Lee, S.H. Jung, S.Y. Lee, Y.H. You, K.H. Ko, Correlation between Al2O3 particles and interface of Al-Al2O3 coatings by cold spray, Appl. Surf. Sci. 252 (2005) 1891-1898.

[34] H.S. Grewal, H.S. Arora, A. Agrawal, H. Singh, S. Mukherjee, Slurry erosion of thermal spray coatings: Effect of sand concentration, Procedia Eng. 68 (2013) 484-490.

[35] R.J.K. Wood, Y. Puget, K.R. Trethewey, K. Stokes, The performance of marine coatings and pipe materials under fluid-borne sand erosion, Wear. 219 (1998) 46-59.

[36] Oerlikon Metco, Material Product Data Sheet Chromium Carbide - Nickel Chromium Powder Blends, 2 (2014) 2-7. 
[37] Oerlikon Metco, Material Product Data Sheet Tungsten Carbide - $10 \%$ Cobalt $4 \%$ Chromium Powders, (2015) 1-7.

[38] Sandvik Osprey, Material Product Data Sheet 316L Powder, 2015.

[39] International ASTM Standard, ASTM A666 - 15 Standard specification for annealed or cold-worked austenitic stainless steel, 1 (1999) 1-7.

[40] H. Assadi, T. Schmidt, H. Richter, J.O. Kliemann, K. Binder, F. Gartner, et al., On parameter selection in cold spraying, J. Therm. Spray Technol. 20 (2011) 1161-1176.

[41] Y.N. Zhang, X. Cao, S. Larose, P. Wanjara, Review of tools for friction stir welding and processing, Can. Metall. Q. 51 (2012) 250-261.

[42] R. Miranda, J. Gandra, P. Vilaca, L. Quintino, T. Santos, Surface Modification by Solid State Processing, Woodhead Publishing Limited, 2008.

[43] International ASTM Standard, ASTM E2109 - 01: Standard Test Methods for Determining Area Percentage Porosity in Thermal Sprayed Coatings, (2006) 1-8.

[44] H.S. Khare, D.L. Burris, A quantitative method for measuring nanocomposite dispersion, Polymer (Guildf). 51 (2010) 719-729.

[45] A.C. Fischer-Cripps, Mechanical Engineering Series: Nanoindentation, 2011.

[46] W.C. Oliver, G.M. Pharr, An improved technique for determining hardness and elastic modulus using load and displacement sensing indentation experiments, J. Mater. Res. 7 (1992) 1565-1583.

[47] International ASTM Standard, ASTM E92-16 Standard Test Methods for Vickers Hardness and Knoop Hardness of Metallic, 2016.

[48] J. Yao, F. Zhou, Y. Zhao, H. Yin, N. Li, Investigation of erosion of stainless steel by twophase jet impingement, Appl. Therm. Eng. (2014) 1-10.

[49] A. Neville, T. Hodgkiess, J.T. Dallas, A study of the erosion-corrosion behaviour of engineering steels for marine pumping applications, Wear. 186-187 (1995) 497-507.

[50] S. Turenne, M. Fiset, J. Masounave, The effect of sand concentration on the erosion of materials by a slurry jet, Wear. 133 (1989) 95-106.

[51] S.S. Rajahram, T.J. Harvey, R.J.K. Wood, Erosion-corrosion resistance of engineering materials in various test conditions, Wear. 267 (2009) 244-254.

[52] R.S. Bolton-King, J.P.O. Evans, C.L. Smith, J.D. Painter, D.F. Allsop, W.M. Cranton, What are the Prospects of 3D Profiling Systems Applied to Firearms and Toolmarks Identification?, AFTE J. 42 (2010) 23-33.

[53] M. Couto, S. Dosta, M. Torrell, J. Fernández, J.M. Guilemany, Cold spray deposition of WC-17 and 12Co cermets onto aluminum, Surf. Coatings Technol. 235 (2013) 54-61.

[54] C.J. Lee, J.C. Huang, P.J. Hsieh, Mg based nano-composites fabricated by friction stir processing, Scr. Mater. 54 (2006) 1415-1420.

[55] A. Toumpis, A. Galloway, S. Cater, N. McPherson, Development of a process envelope for friction stir welding of DH36 steel - A step change, Mater. Des. 62 (2014) 64-75.

[56] R. Bauri, D. Yadav, G. Suhas, Effect of friction stir processing (FSP) on microstructure and properties of Al-TiC in situ composite, Mater. Sci. Eng. A. 528 (2011) 4732-4739.

[57] I. Finnie, Erosion of surfaces by solid particles, Wear. 3 (1960) 87-103.

[58] D. Aquaro, E. Fontani, Erosion of ductile and brittle materials, Meccanica. 36 (2001) 651661.

[59] T. Peat, A. Galloway, A. Toumpis, D. Harvey, W.H. Yang, Performance evaluation of HVOF deposited cermet coatings under dry and slurry erosion, Surf. Coatings Technol. 300 (2016) 118-127.

[60] P. Kulu, I. Hussainova, R. Veinthal, Solid particle erosion of thermal sprayed coatings, Wear. 258 (2005) 488-496. 
Fig. 1. Scanning electron micrographs of the feedstock powder particles [x800]. a) WC-CoCr; b) $\mathrm{Al}_{2} \mathrm{O}_{3}$

Fig. 2. Schematic diagram of the cold spray apparatus.

Fig. 3. Macroscopic cross section of the SprayStirred WC-CoCr MMC layer.

Fig. 4. Micrographs that highlight the approx. location of images shown in Fig. 5 [x100]. a) Asdeposited cold spray coating; b) SprayStirred coating

Fig. 5. Light optical micrographs of the WC-CoCr reinforced MMC [x500]. a) As-deposited; b) SprayStirred

Fig. 6. Deformation of the WC-CoCr agglomerates post-FSP [x500].

Fig. 7. Light optical micrographs of the $\mathrm{Al}_{2} \mathrm{O}_{3}$ reinforced $\mathrm{MMC}$ [x500]. a) as-deposited; b) SprayStirred

Fig 8. EDS maps showing the distribution of $\mathrm{Al}_{2} \mathrm{O}_{3}$ reinforcing particles [x500]. a) As-deposited; b) $\mathrm{Al}_{2} \mathrm{O}_{3}$.

Fig. 9. Average microhardness values across the stir zone (Fig. 3).

Fig. 10. Optical micrographs of nanoindentation impressions on the a) as-deposited, b) SprayStirred WC-CoCr reinforced MMC [x500].

Fig. 11. Hardness maps of the examined area: a) WC-CoCr reinforced $M M C$, b) $\mathrm{Al}_{2} \mathrm{O}_{3}$ reinforced MMC.

Fig. 12. Mass loss of the MMC coatings pre- and post-FSP; a) $90^{\circ}$ angle of attack, b) $30^{\circ}$ angle of attack.

Fig. 13. Measured volume loss pre-and post FSP; a) $90^{\circ}$ angle of attack, b) $30^{\circ}$ angle of attack.

Fig. 14. Optical macrographs of the wear scar a) as-received AISI316 at $90^{\circ}$, b) post-FSP AISI316 at $30^{\circ}$

Fig. 15. SEM micrographs of impinged region on the AISI316 [x1500]; a) $90^{\circ}$ [x1500], b) $30^{\circ}$ [x1200].

Fig. 16. SEM micrographs of impinged region on the $\mathrm{WC}-\mathrm{CoCr}$ reinforced $\mathrm{MMC}$ following impingement at $30^{\circ}$; a) As-deposited WC-CoCr [x1200], b) SprayStirred WC-CoCr [x1500].

Fig. 17. SEM micrographs of impinged region on the $\mathrm{Al}_{2} \mathrm{O}_{3}$ reinforced $M M C$ following impingement at $30^{\circ}$; a) As-deposited [x1200], b) SprayStirred [x1500]. 
Click here to download high resolution image
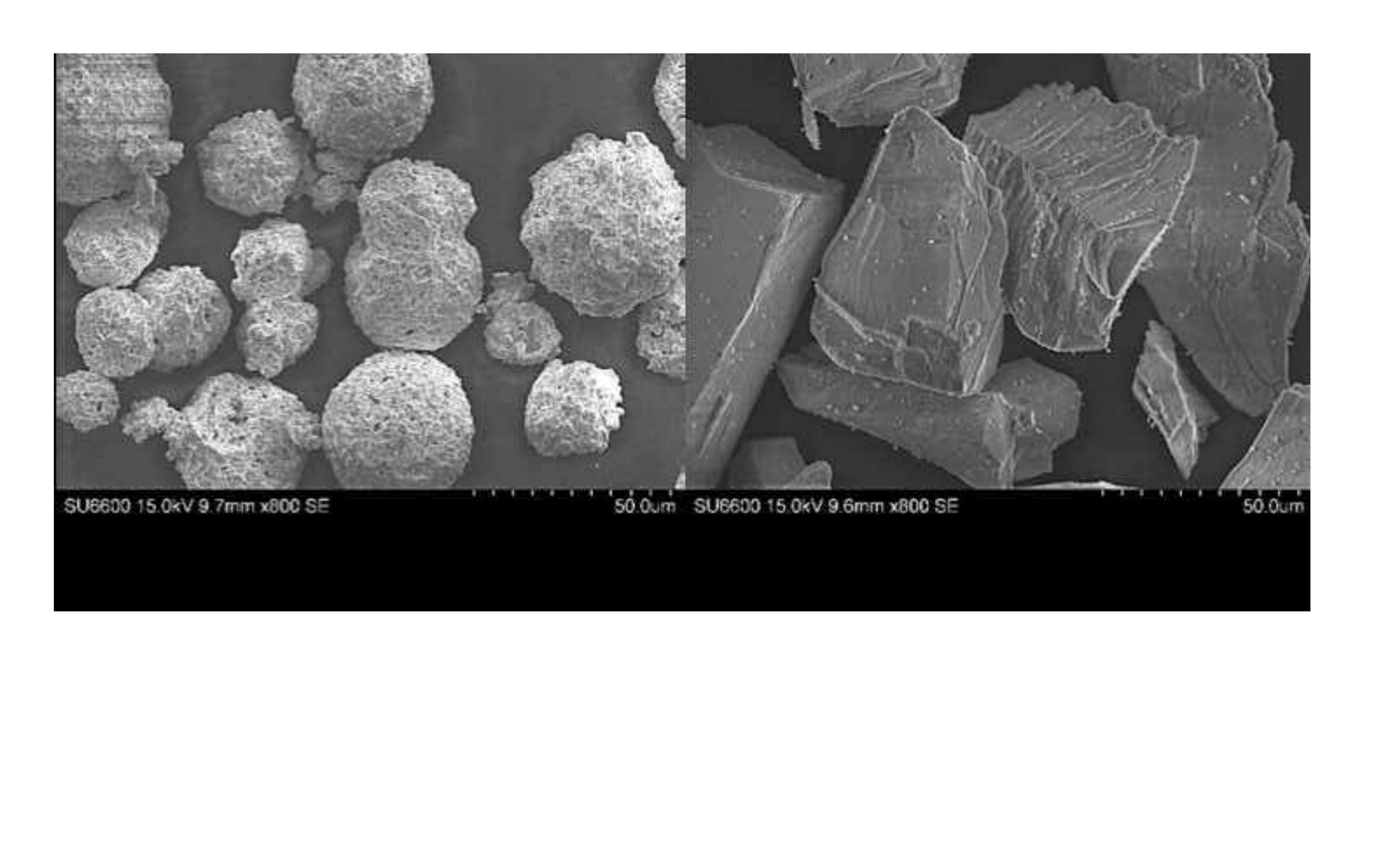
Click here to download high resolution image

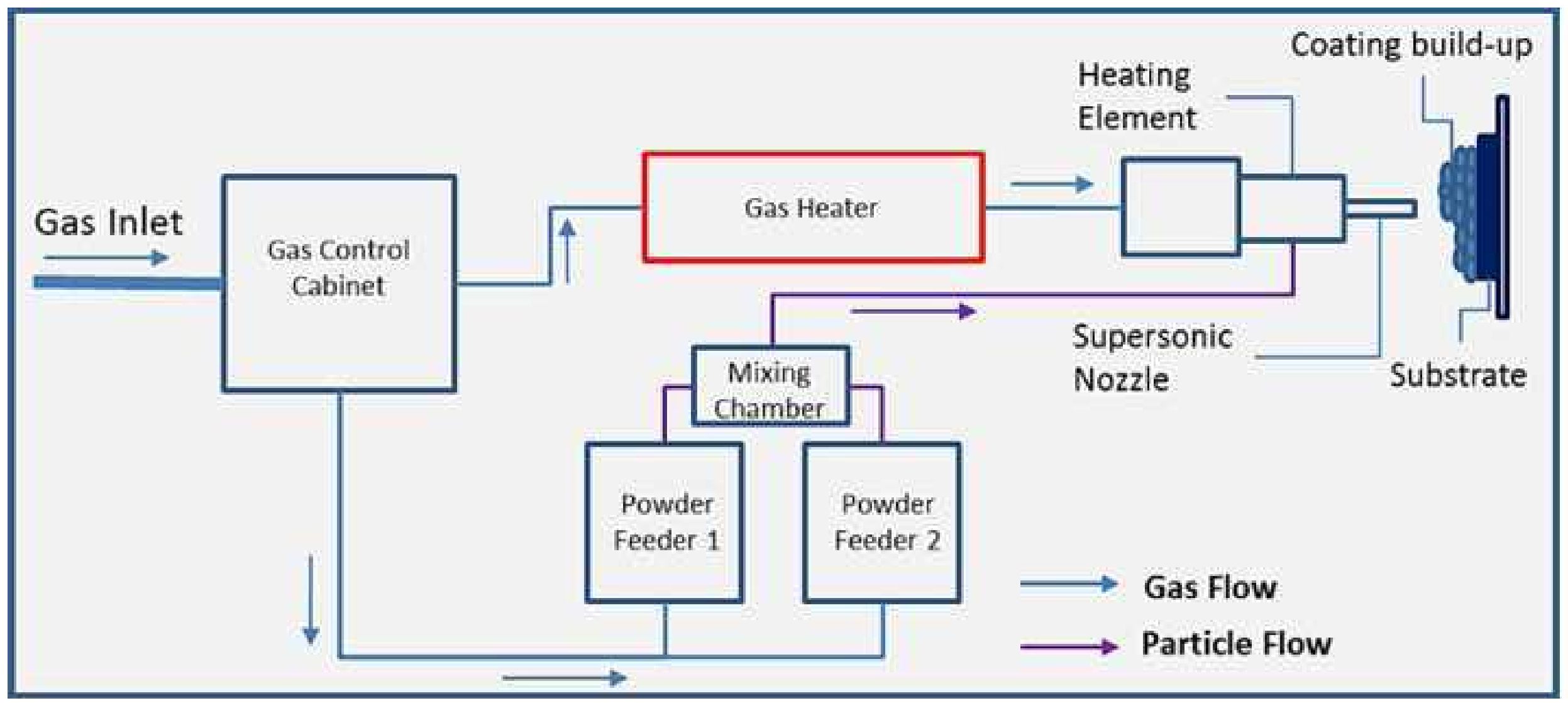

Gas Inlet

Sontro

Supersonic

Substrate

Particle Flow 
Click here to download high resolution image

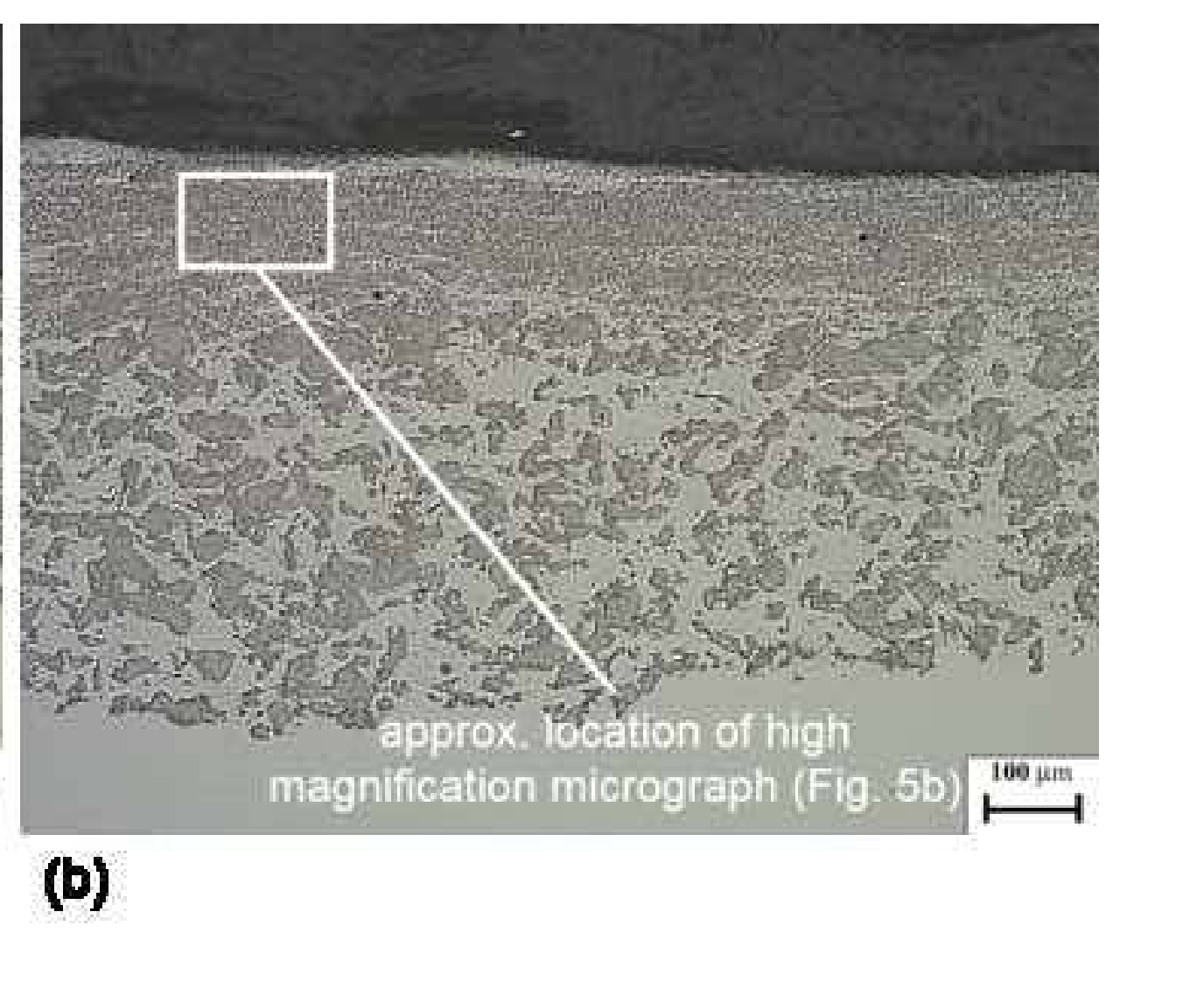

(b)

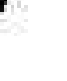

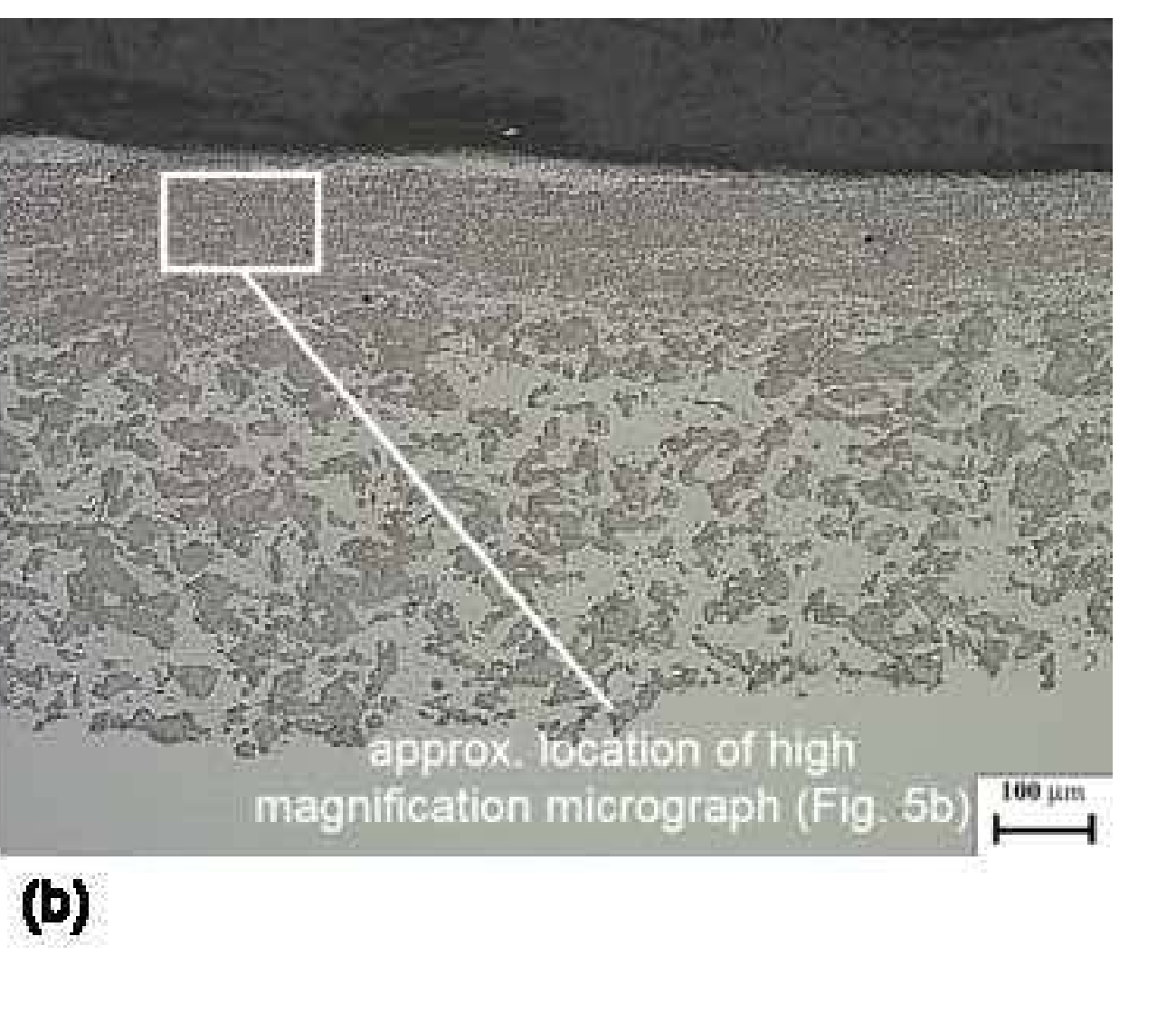

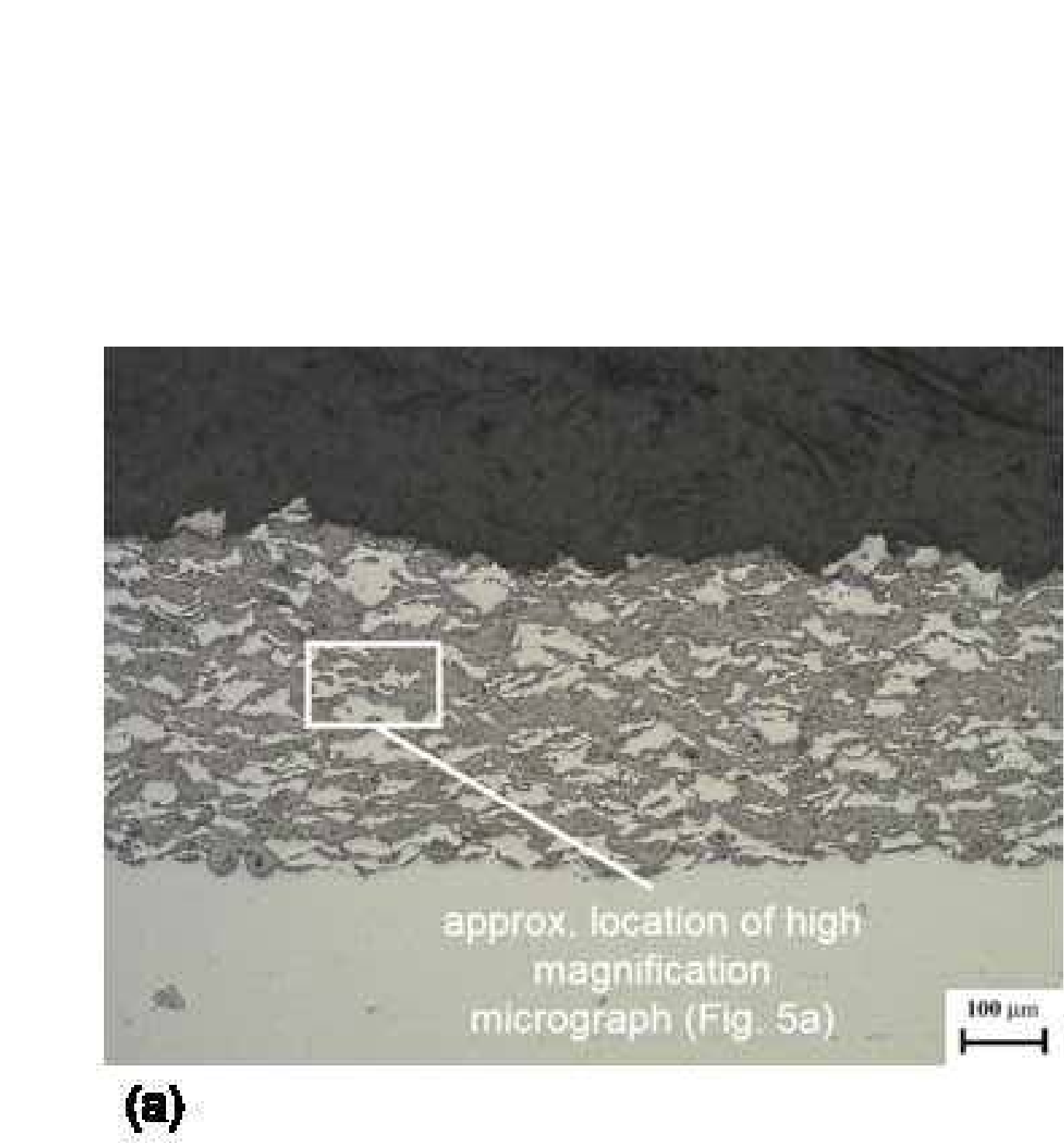

(a)

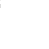

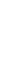
.
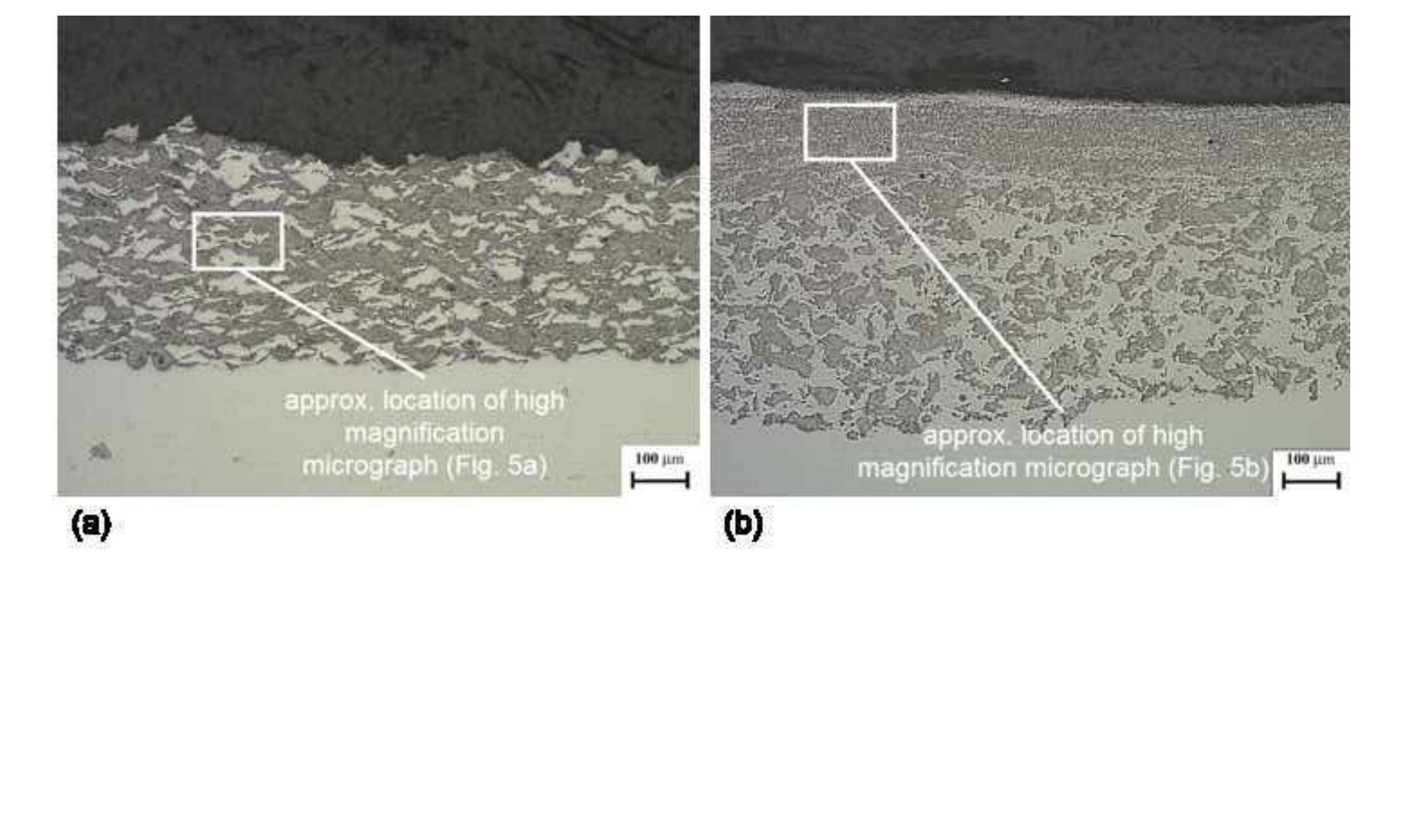
Click here to download high resolution image

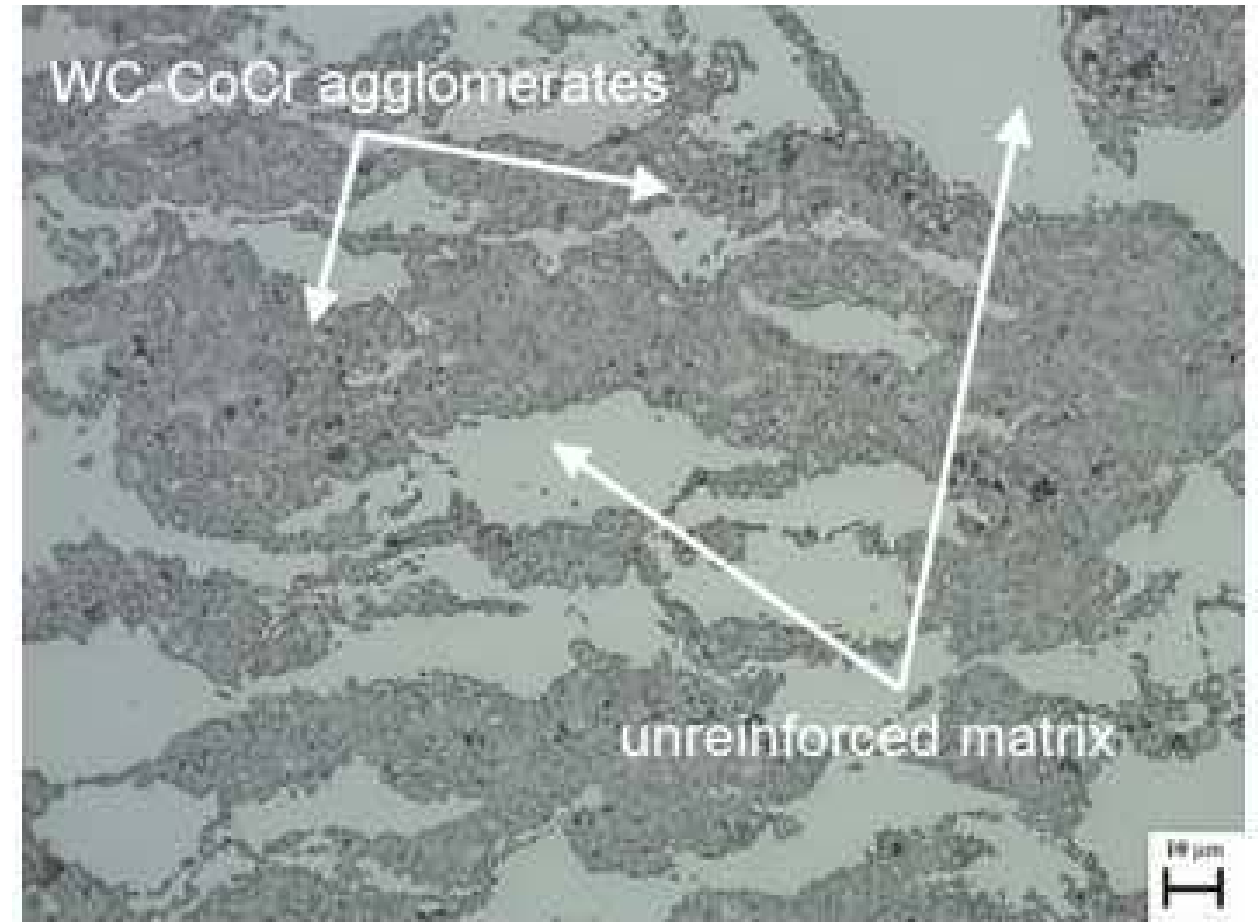

(a)

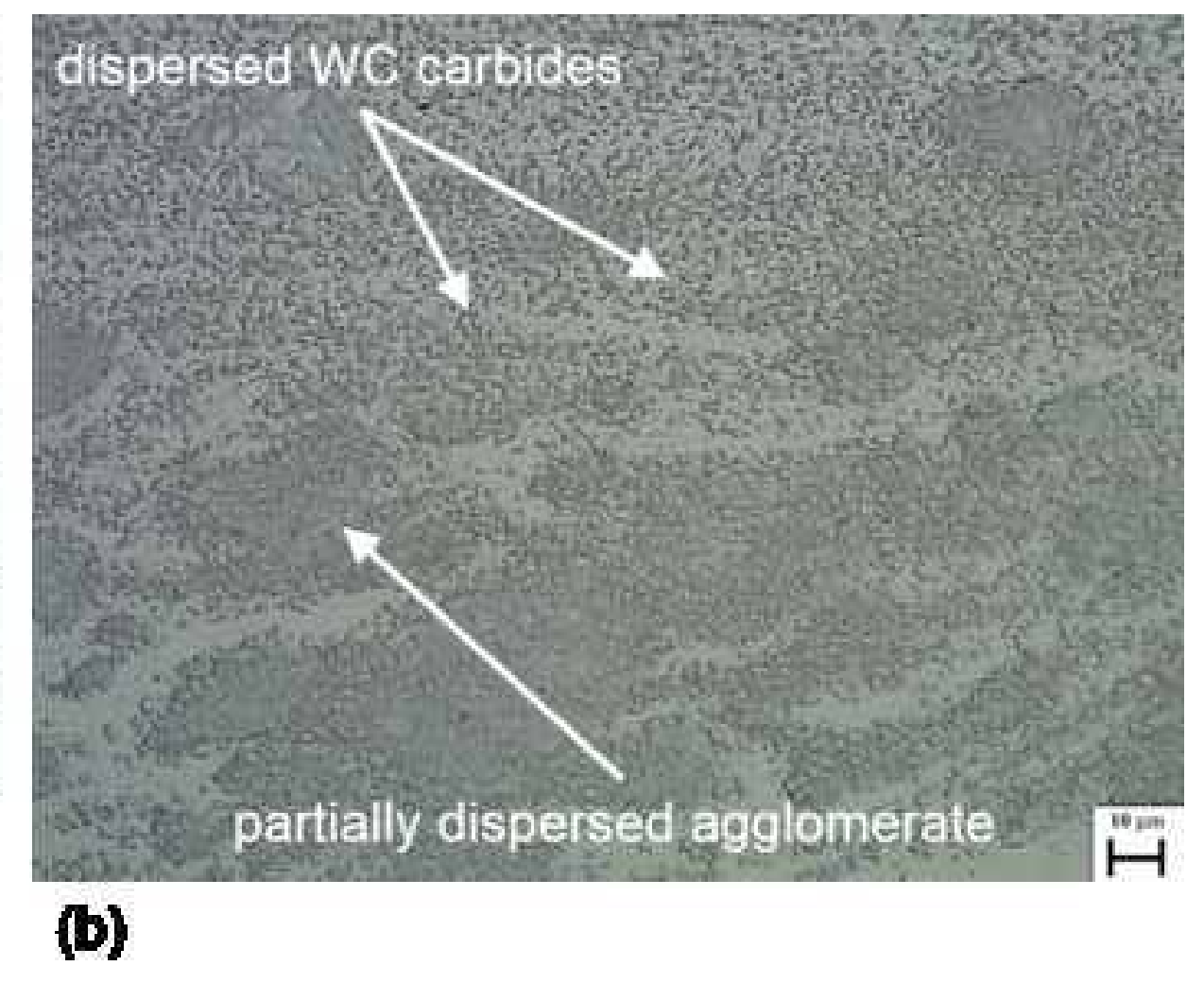

(b)

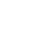

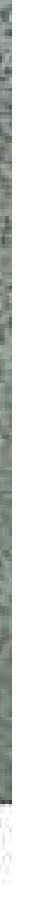




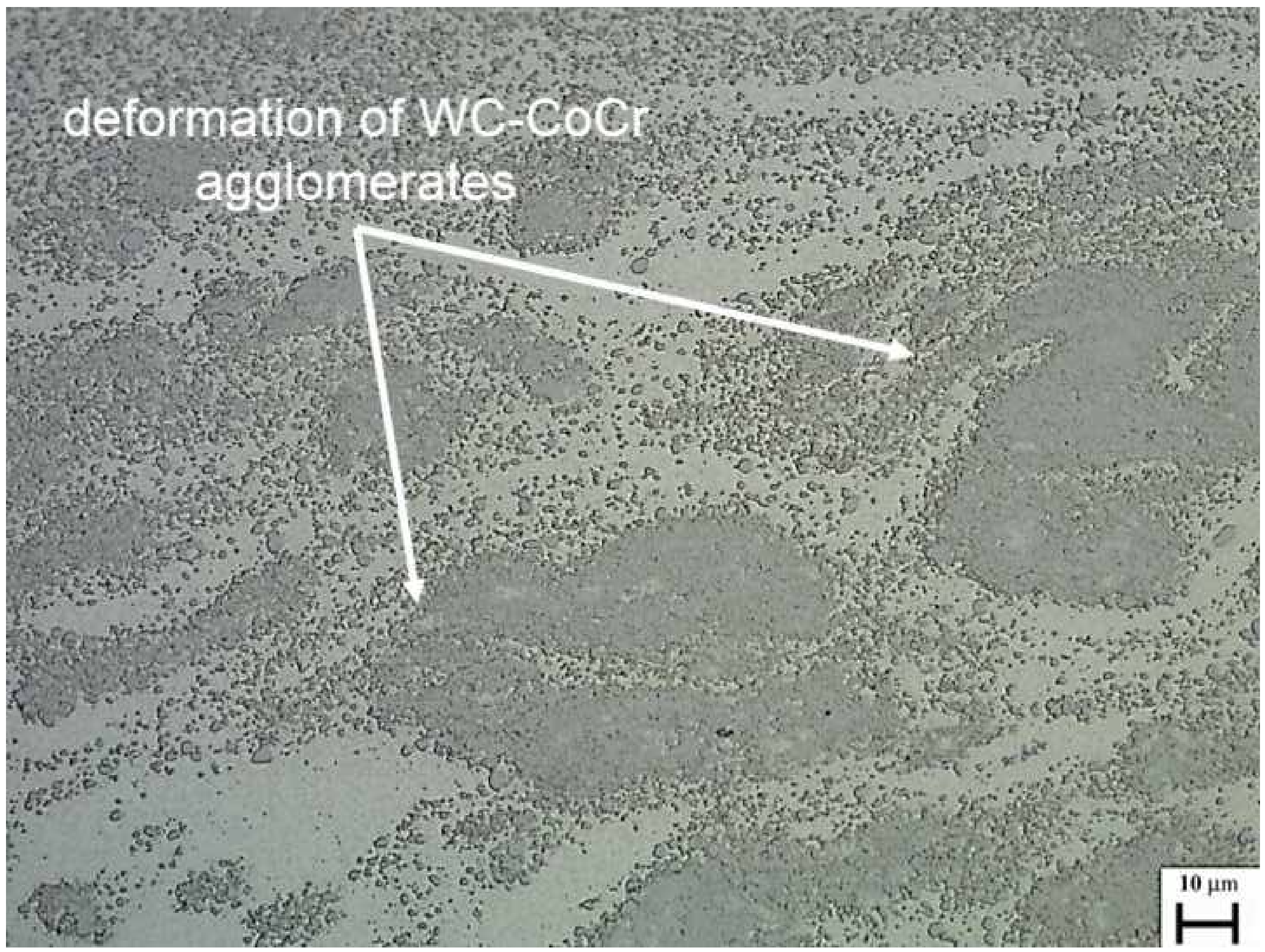


Click here to download high resolution image

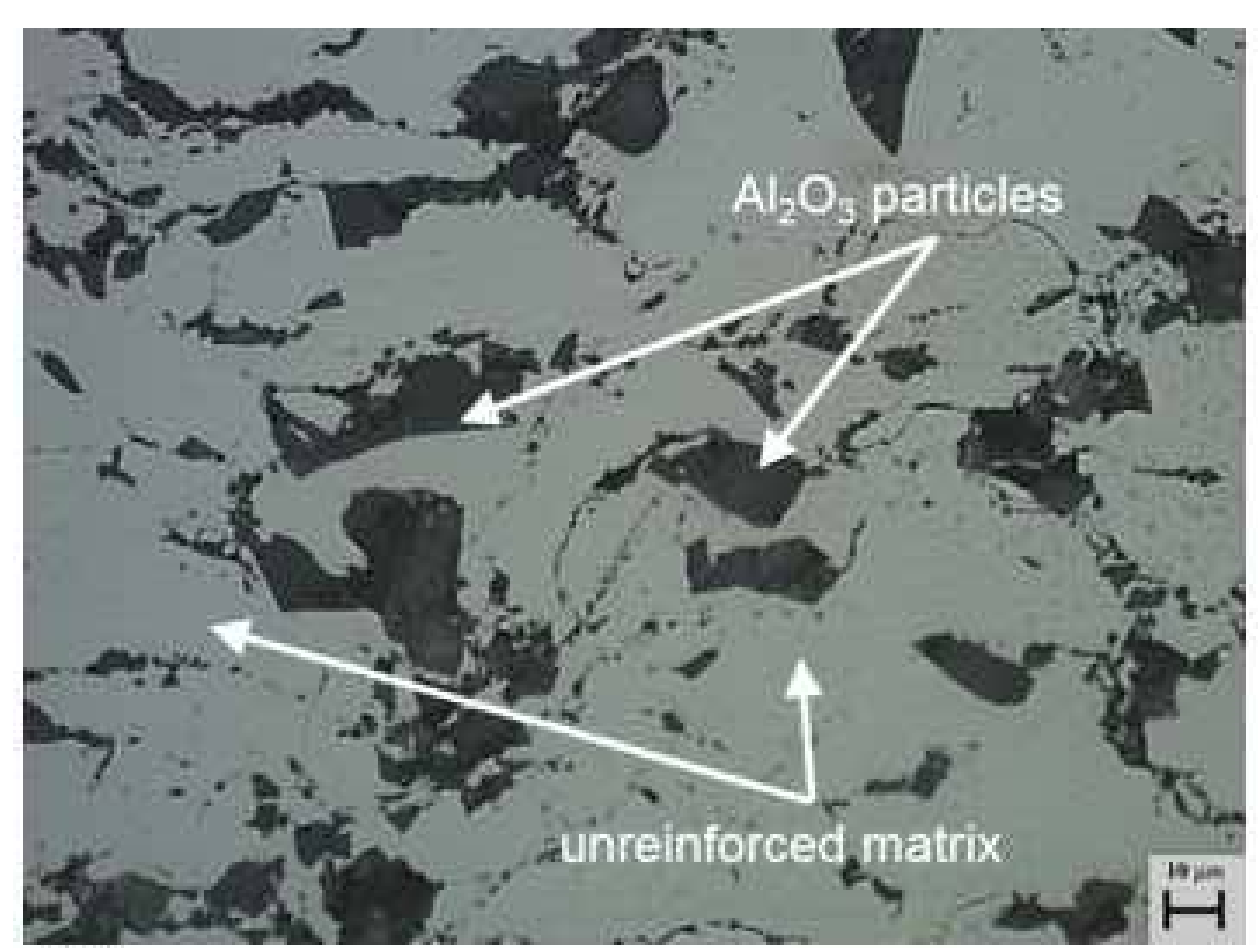

(a)

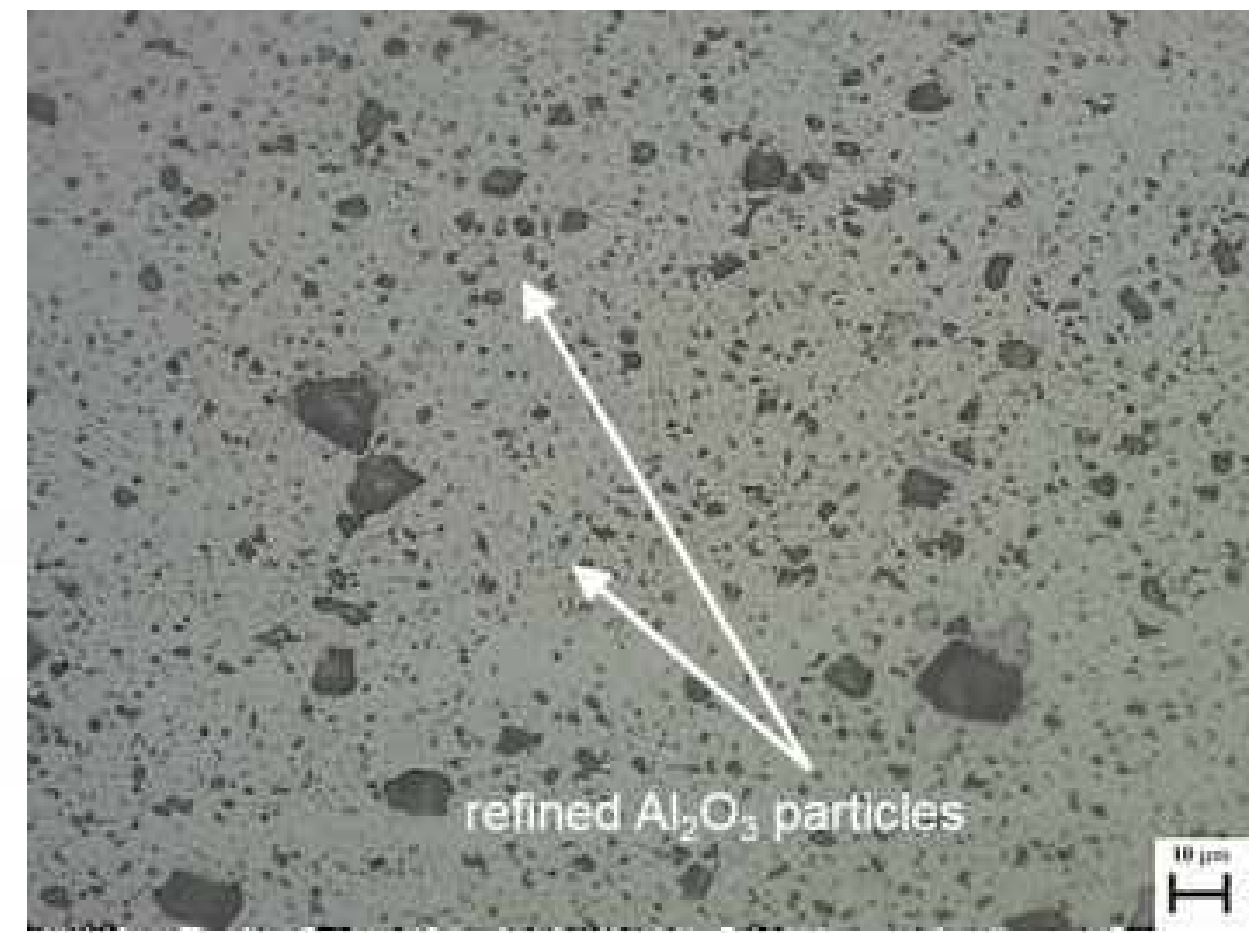

(b) 
Click here to download high resolution image

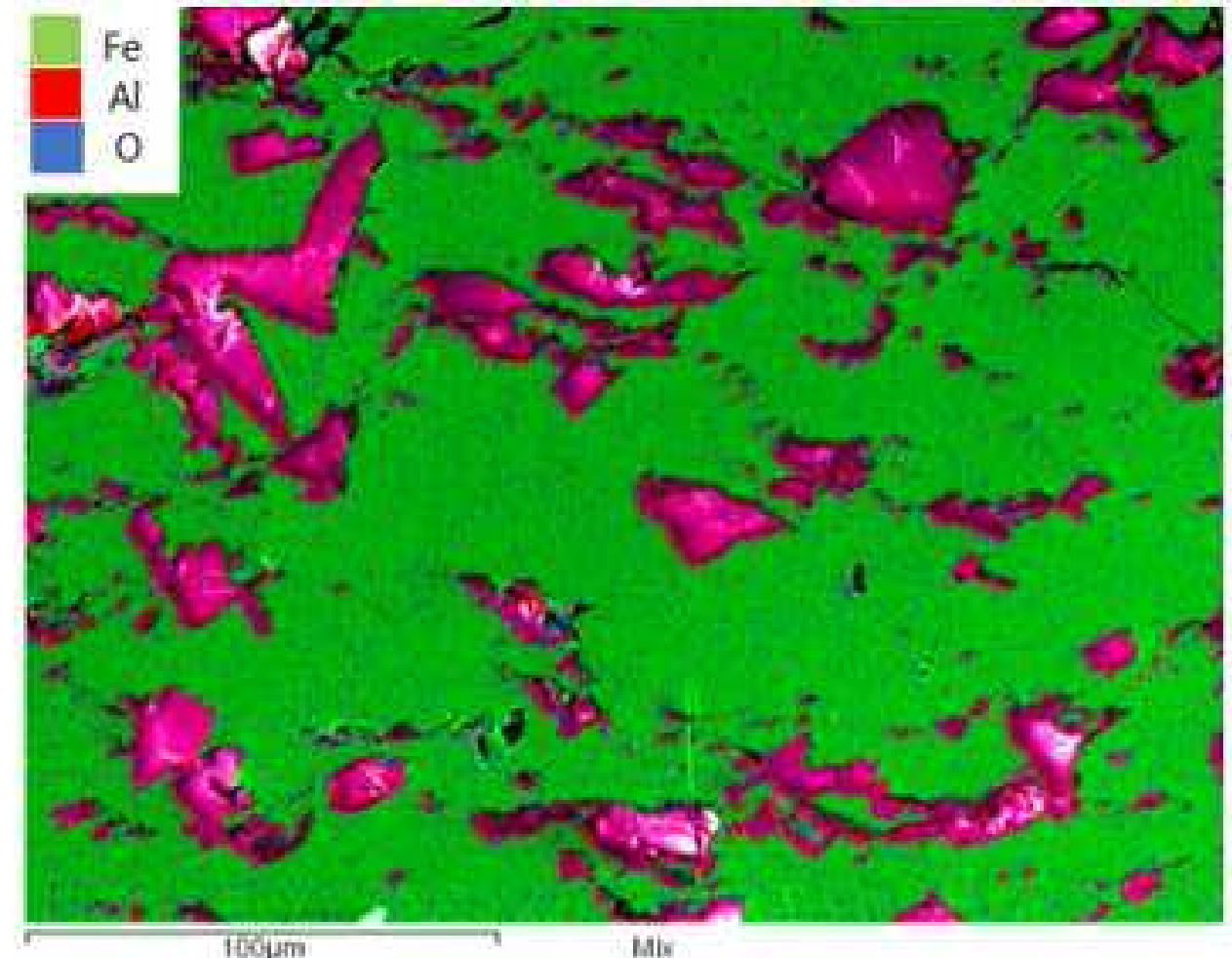

(a)

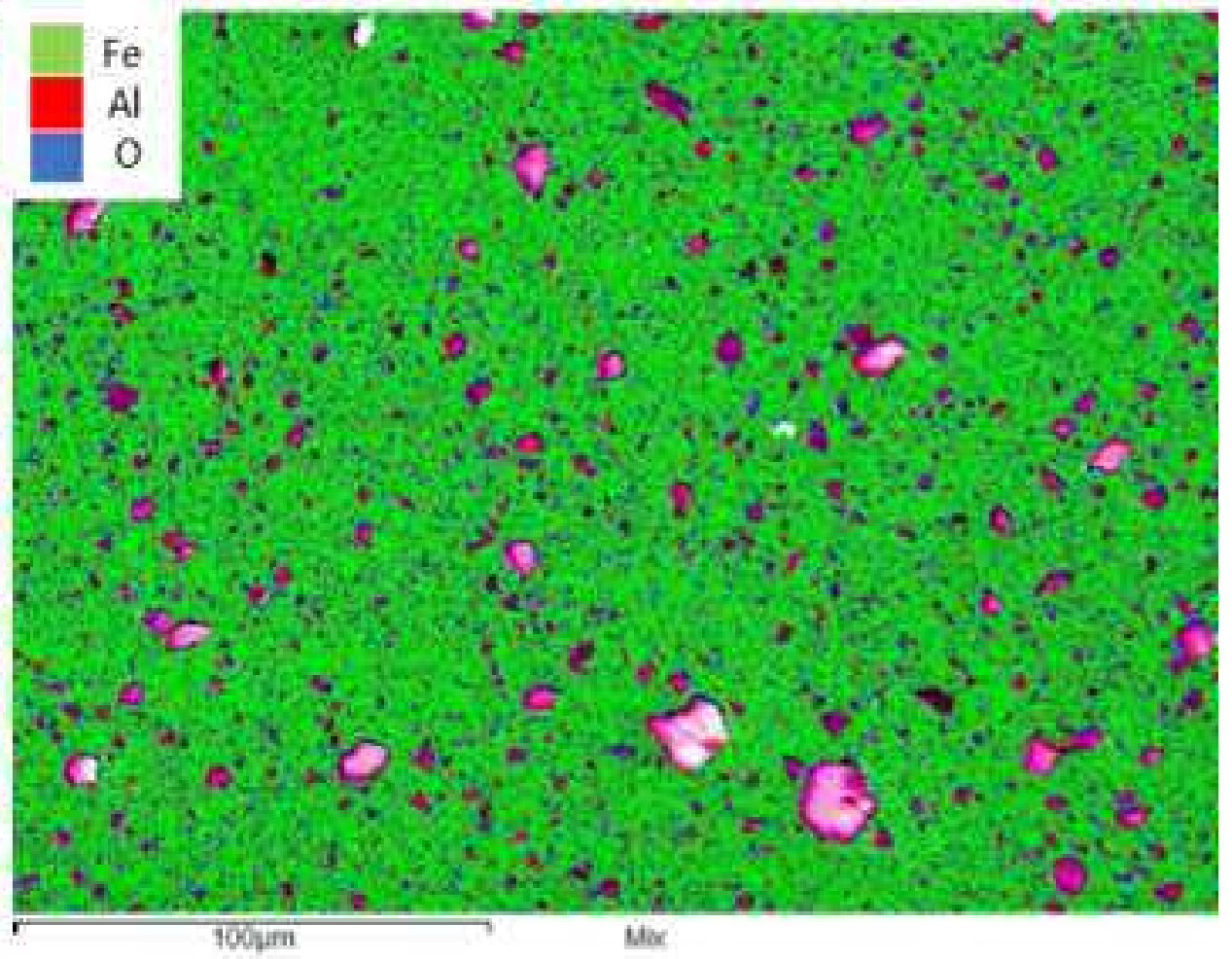

(b)

.


$\leftarrow-$ WC-CoCr $\leftarrow \mathrm{Al}_{2} \mathrm{O}_{3} \leftarrow$ Post-FSP AISI316 - As-recieved AISI316

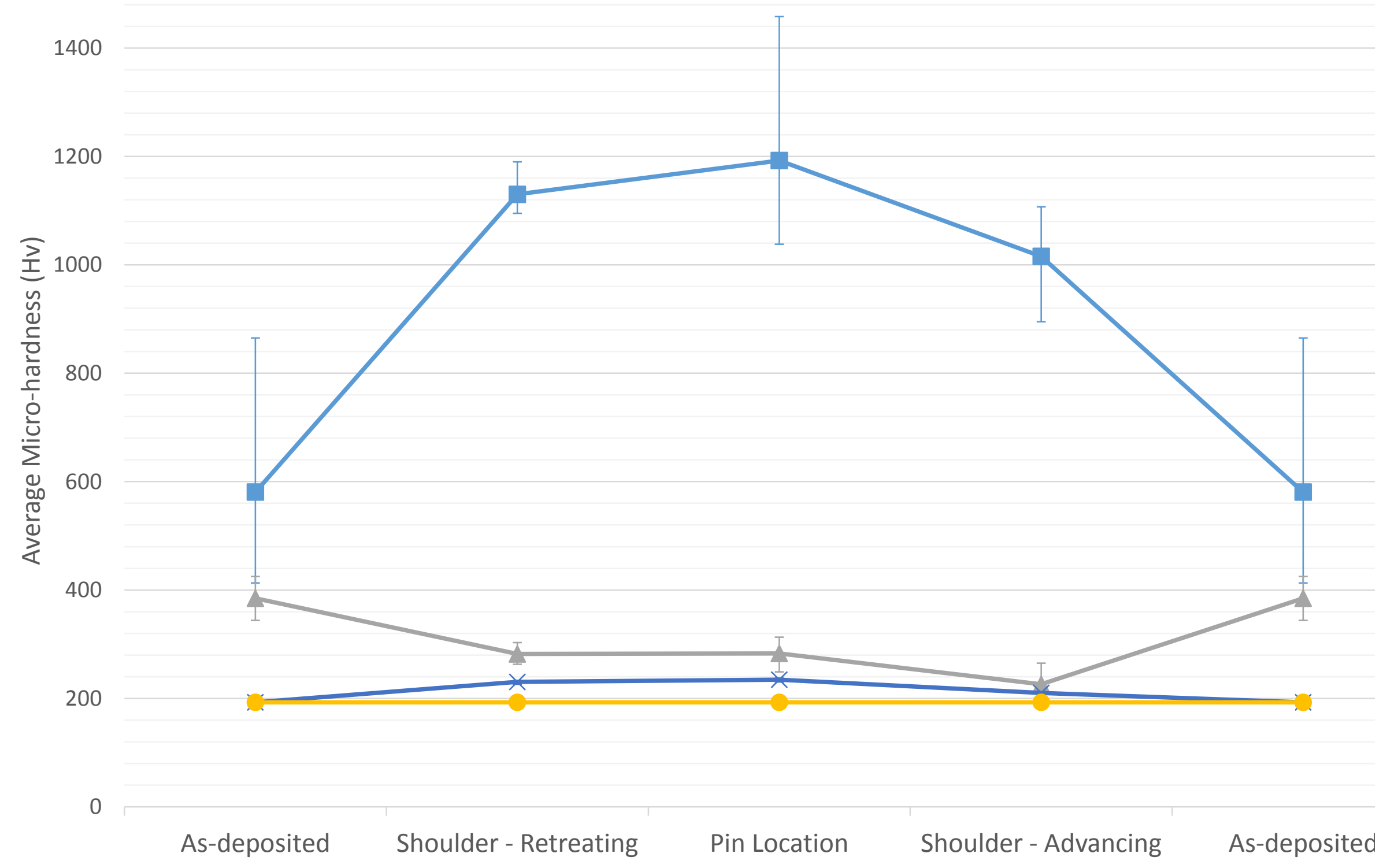


Click here to download high resolution image
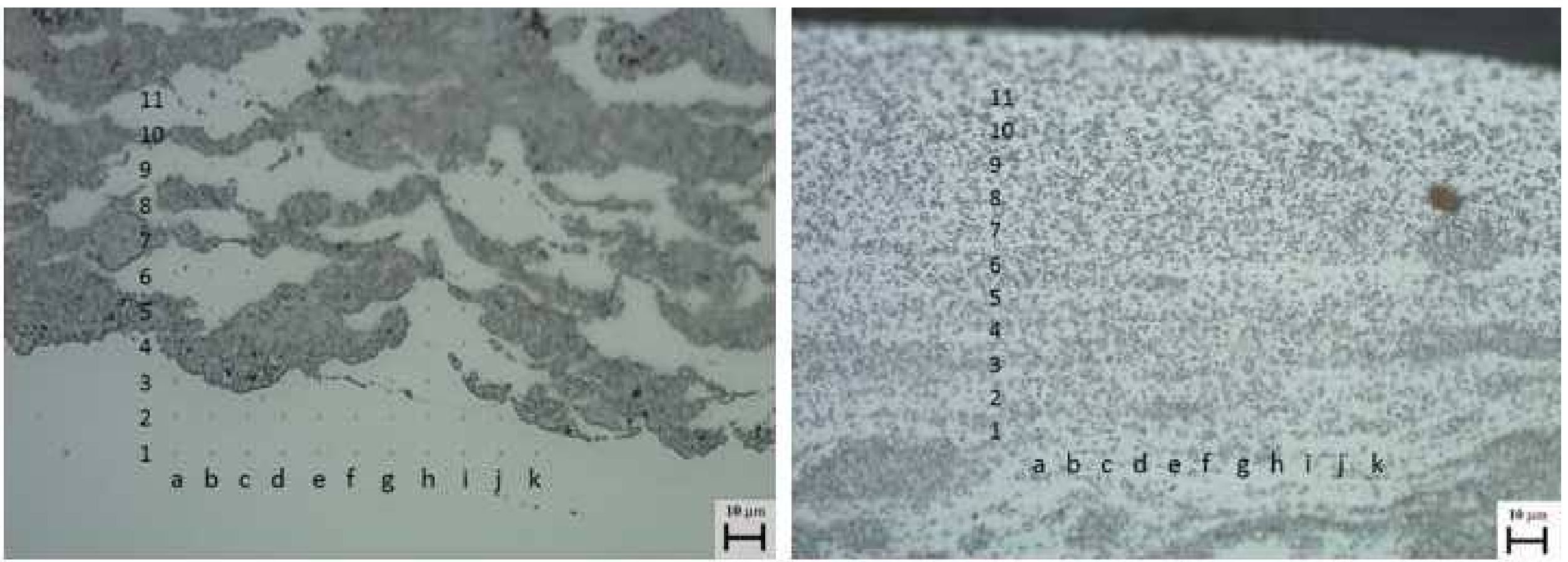

(a)

(b) 


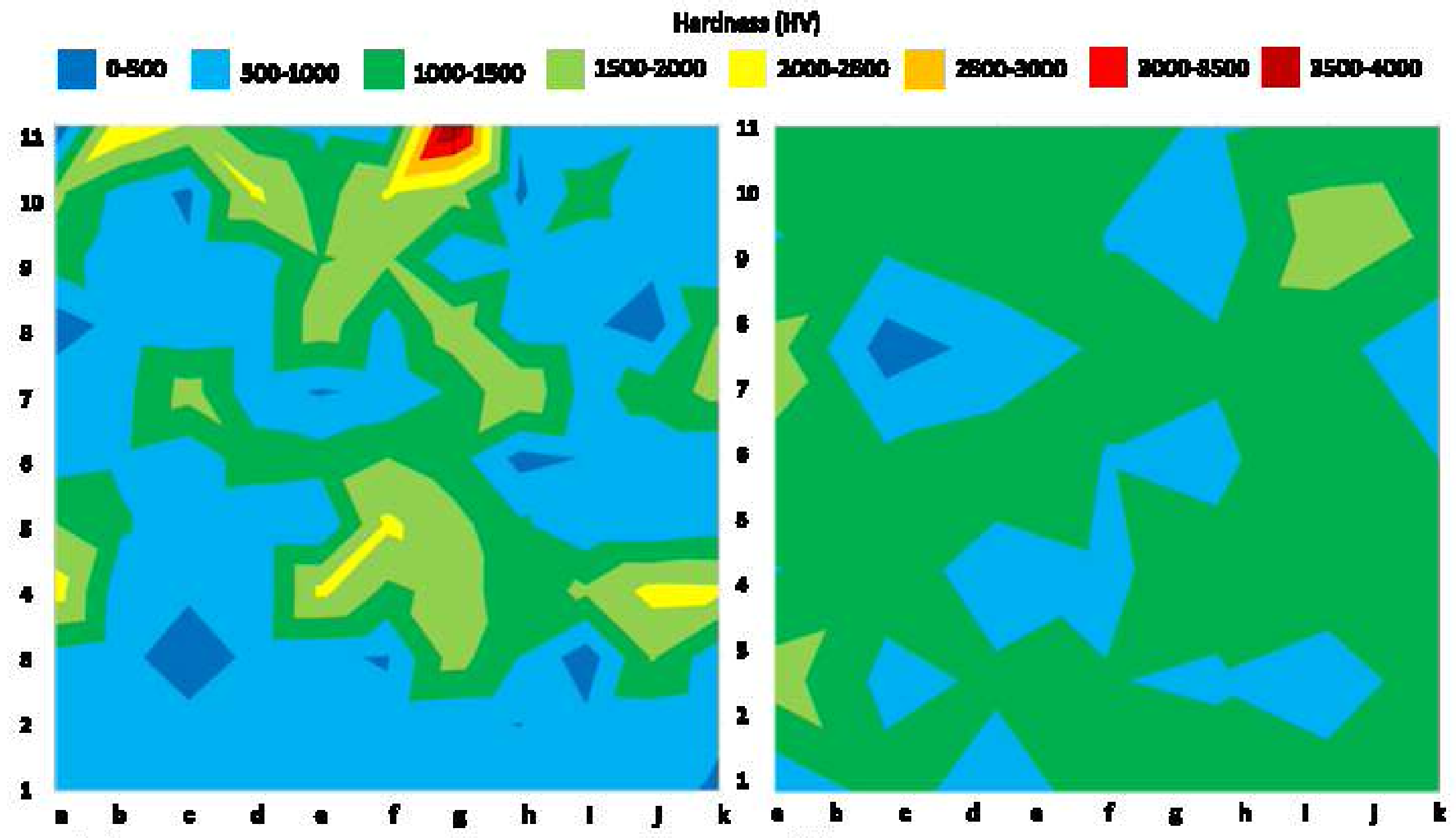

(a)

(b) 


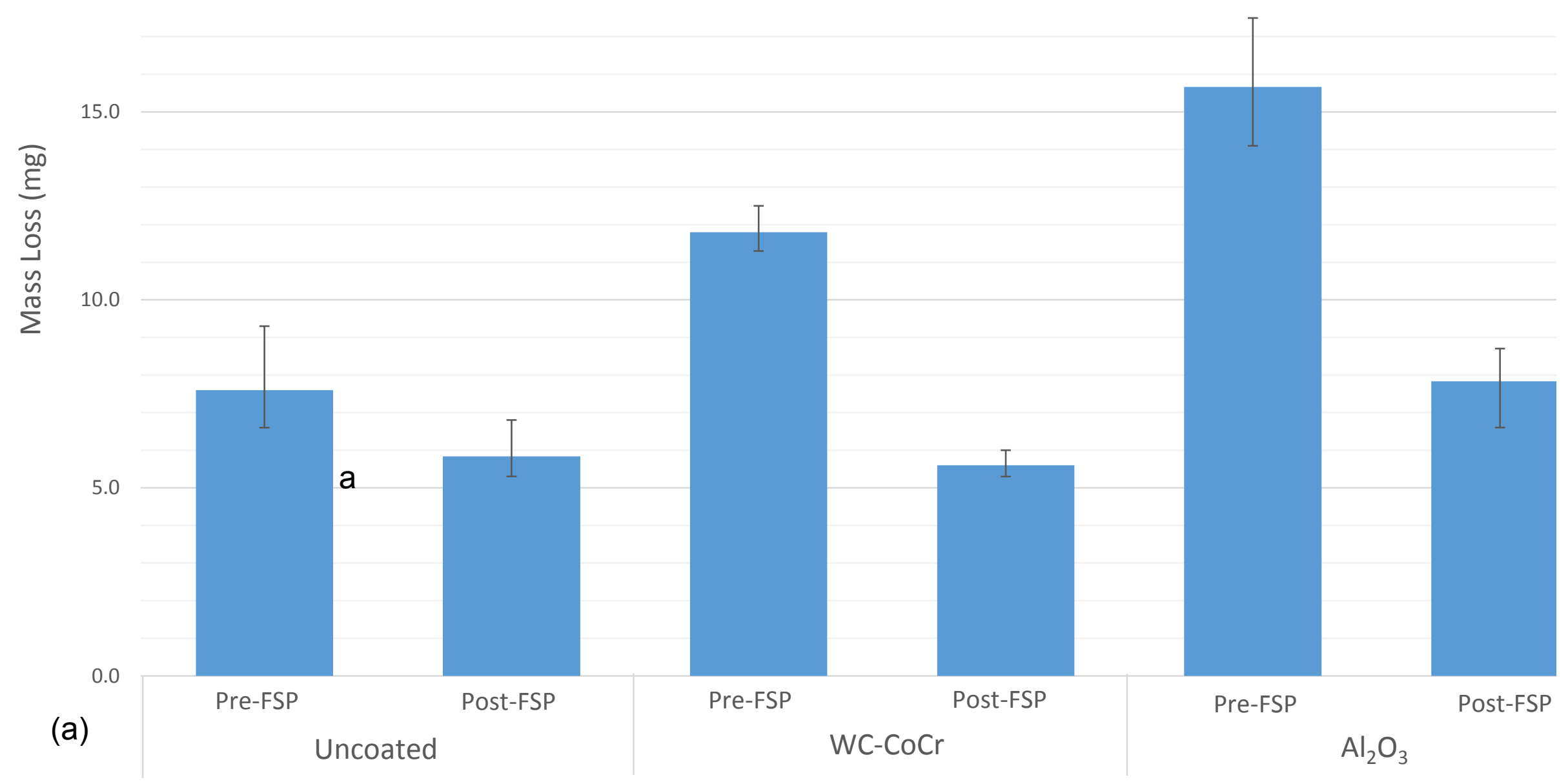


25.0

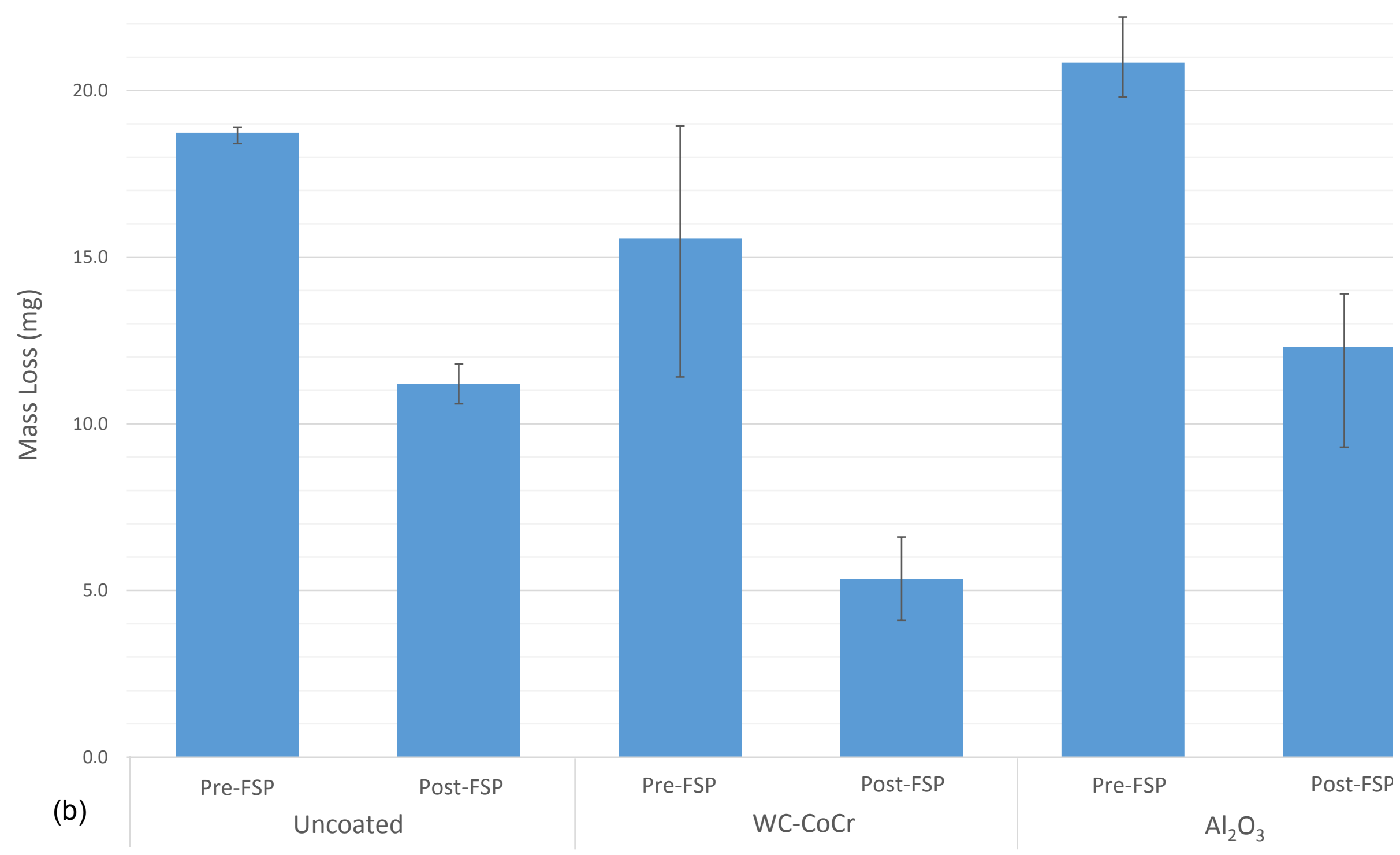


Fig. 13a

2.5

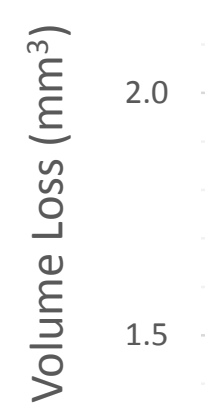

1.0
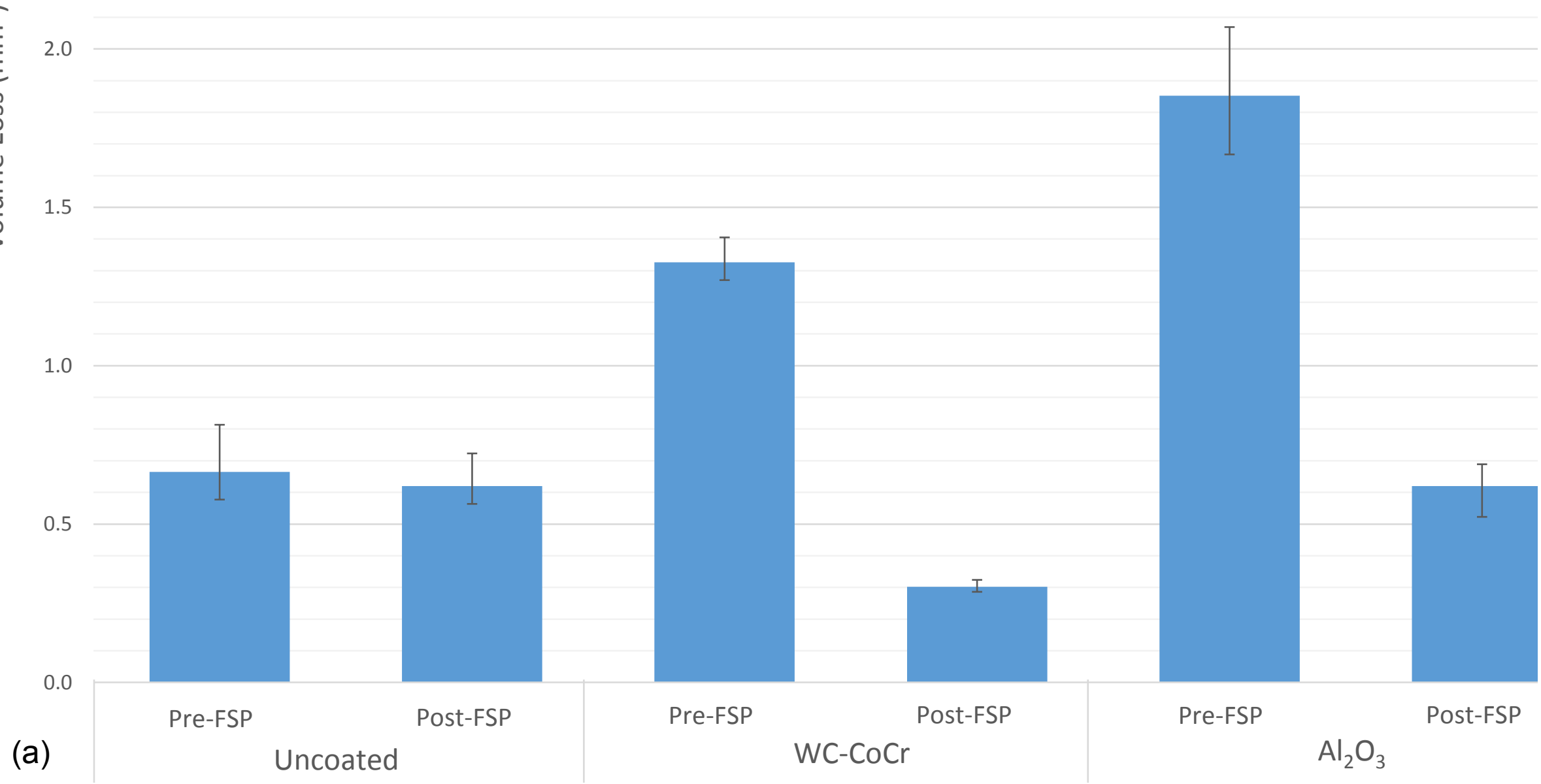
Fig. 13b

3.0

2.5

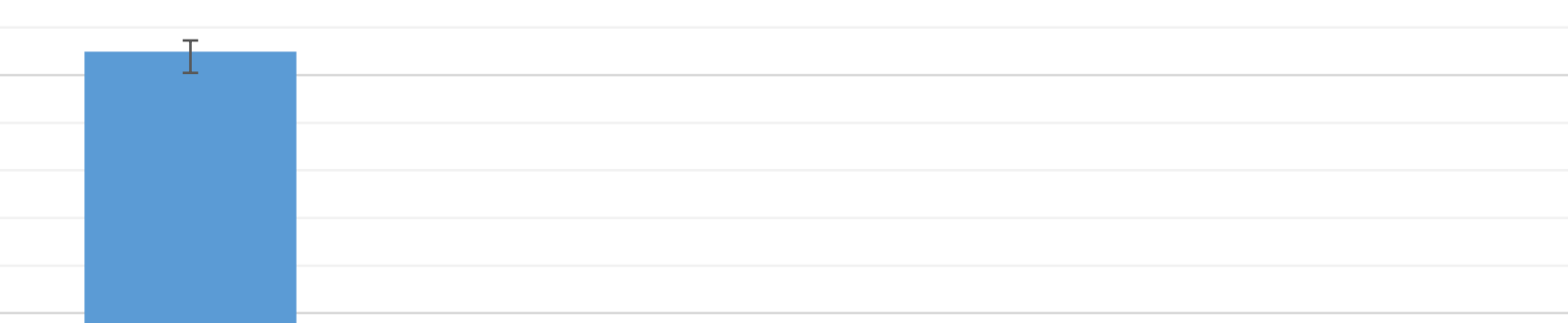

2.0

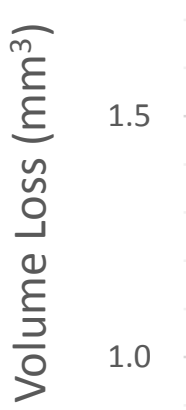

0.5

0.0

(b)

Pre-FSP

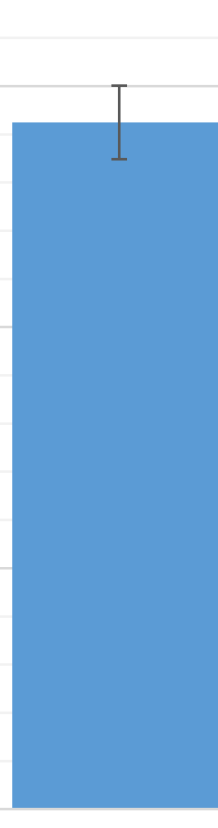

Post-FSP

Uncoated

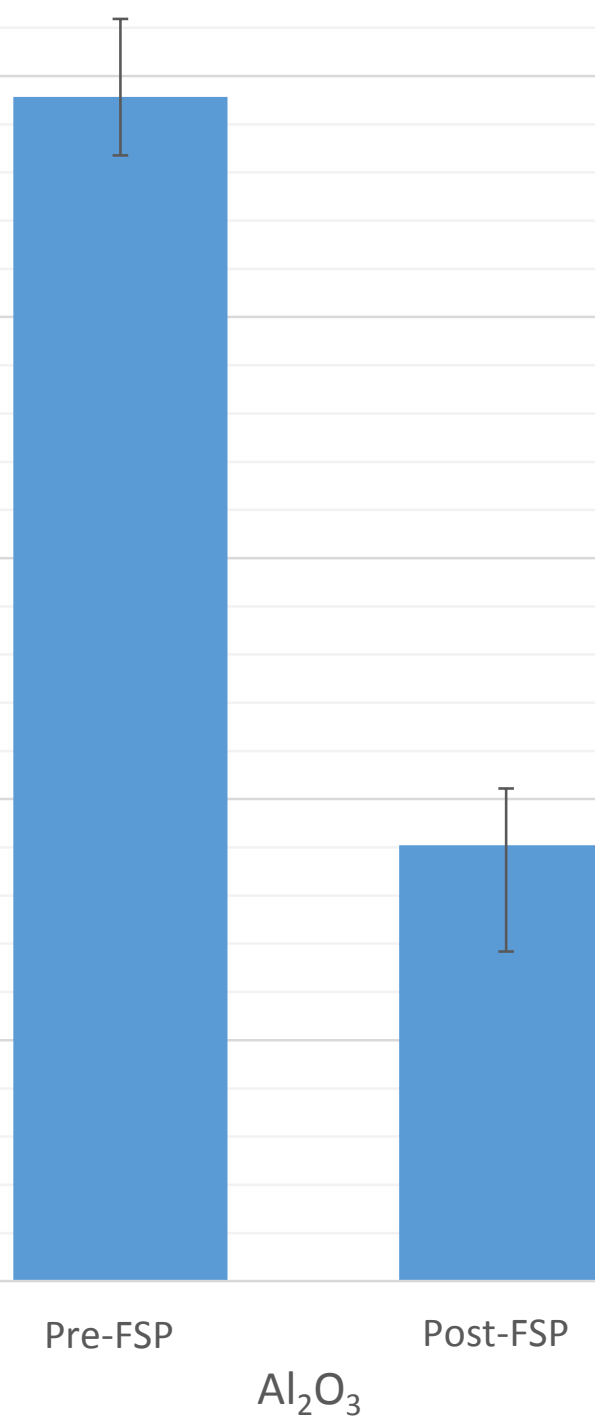




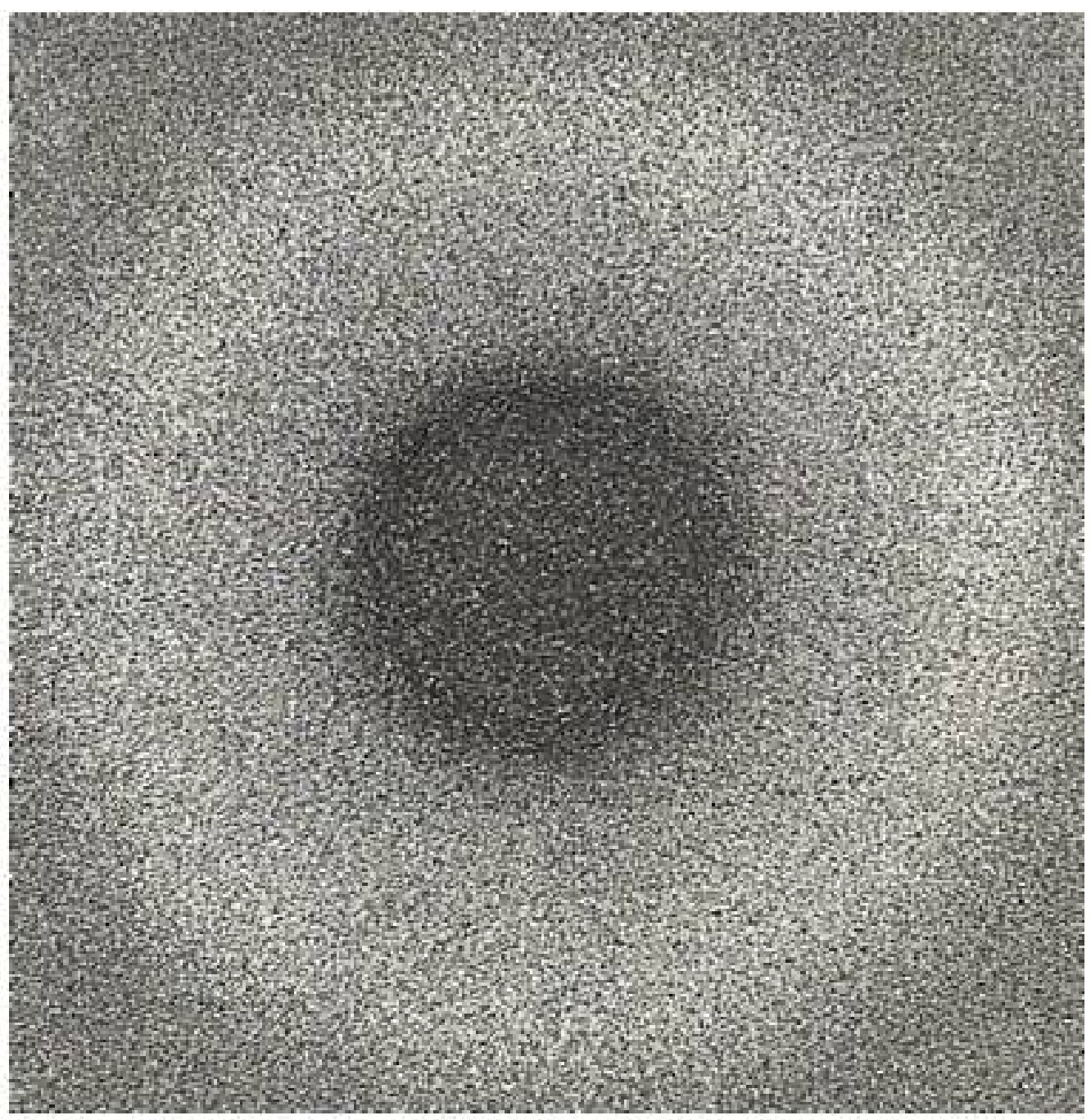

(a)

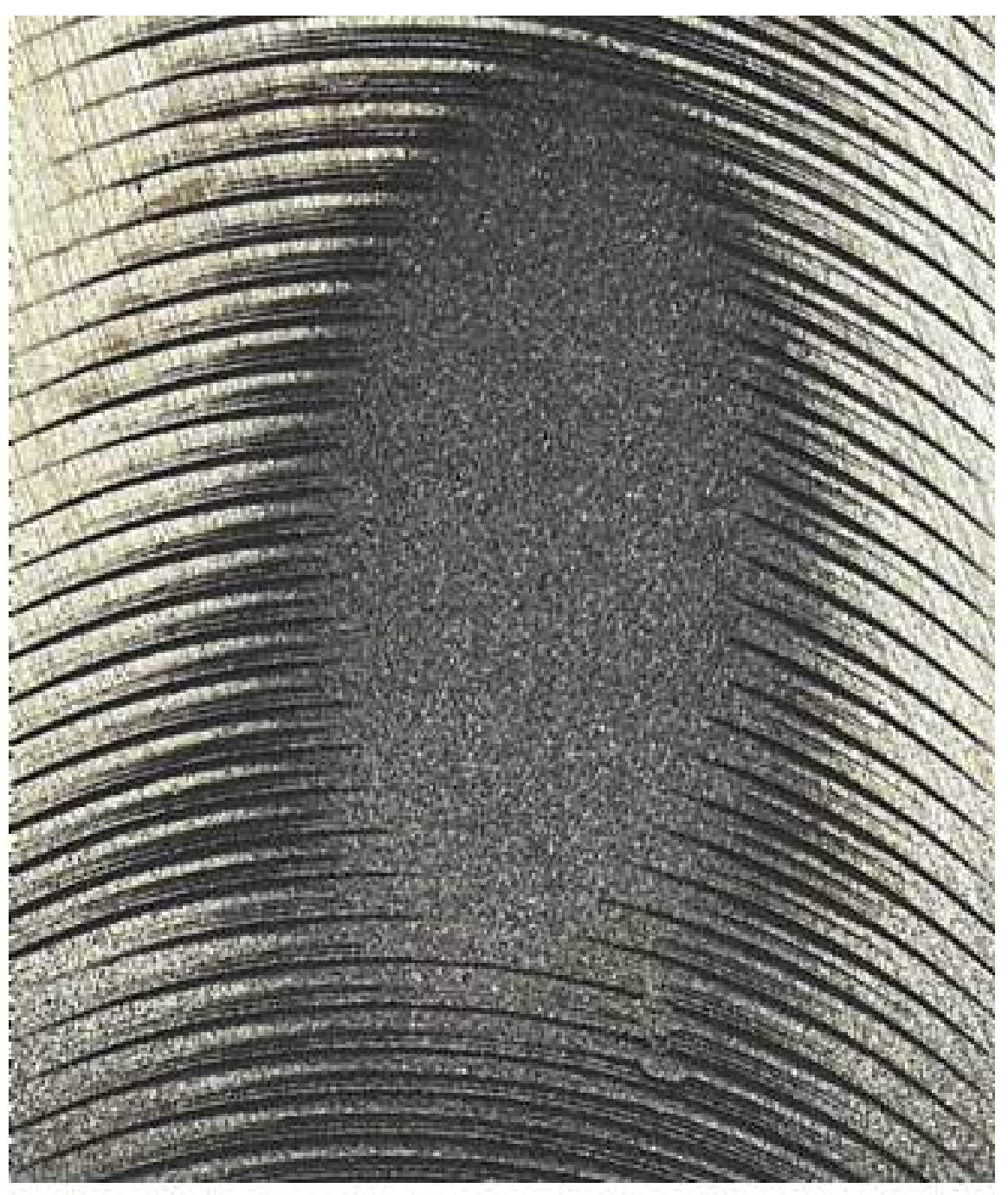

(b) 
Click here to download high resolution image

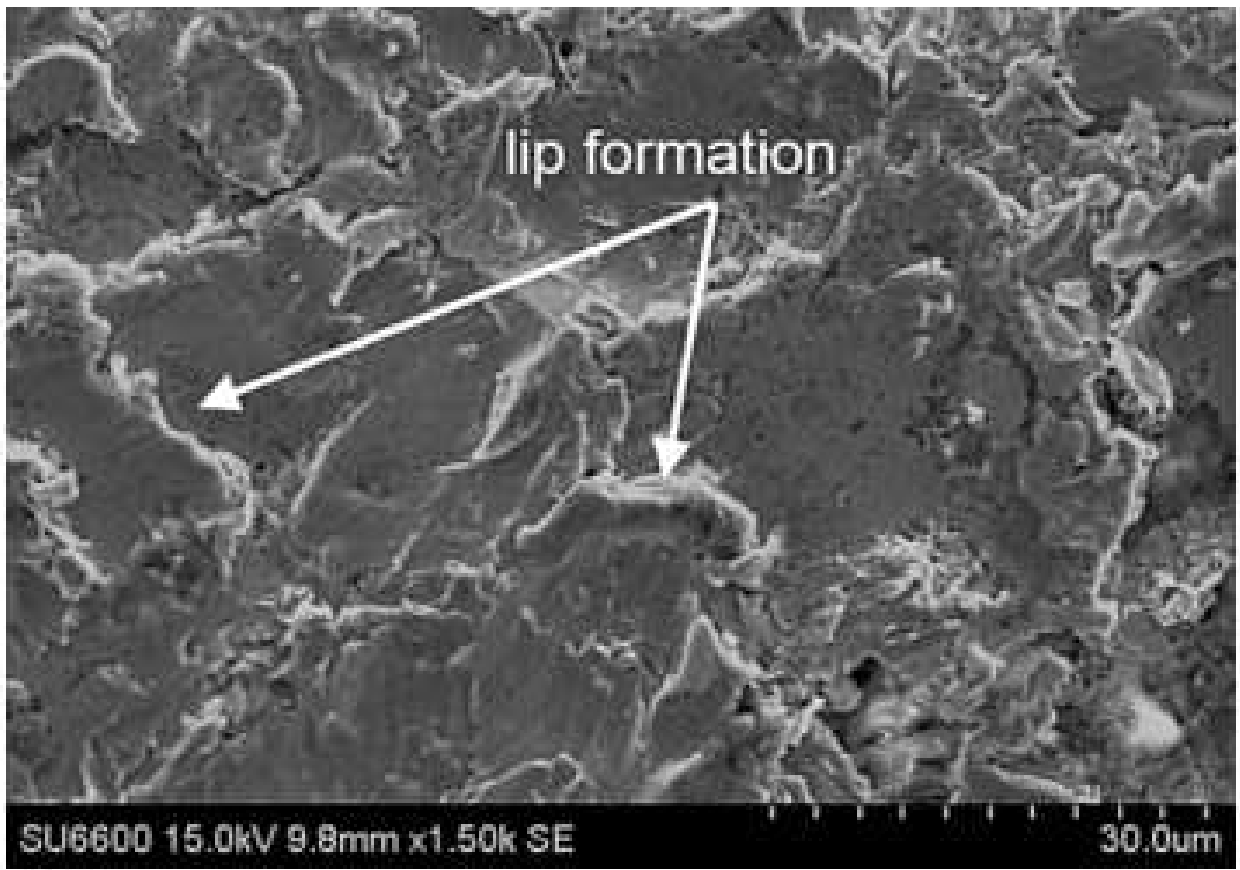

(a)

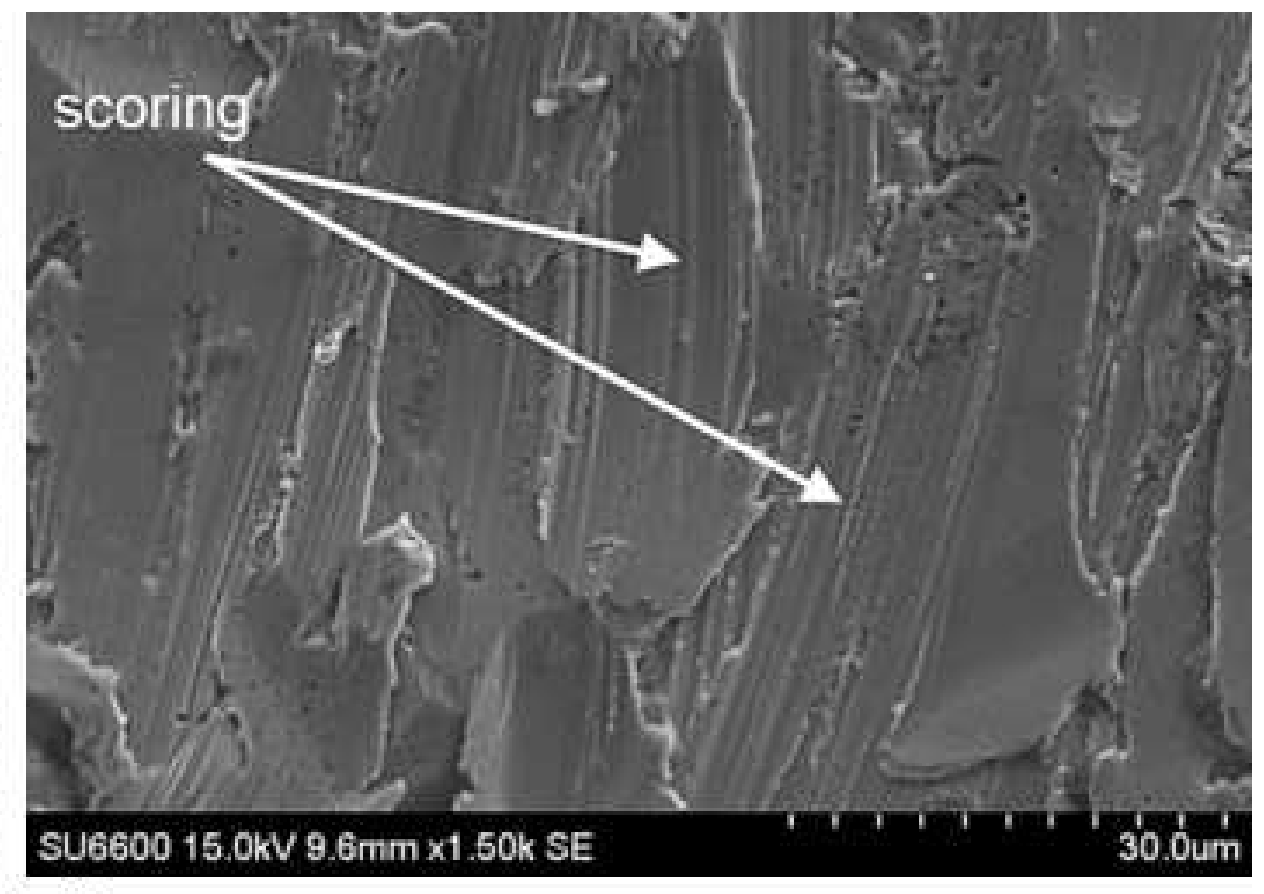

(b) 
Click here to download high resolution image

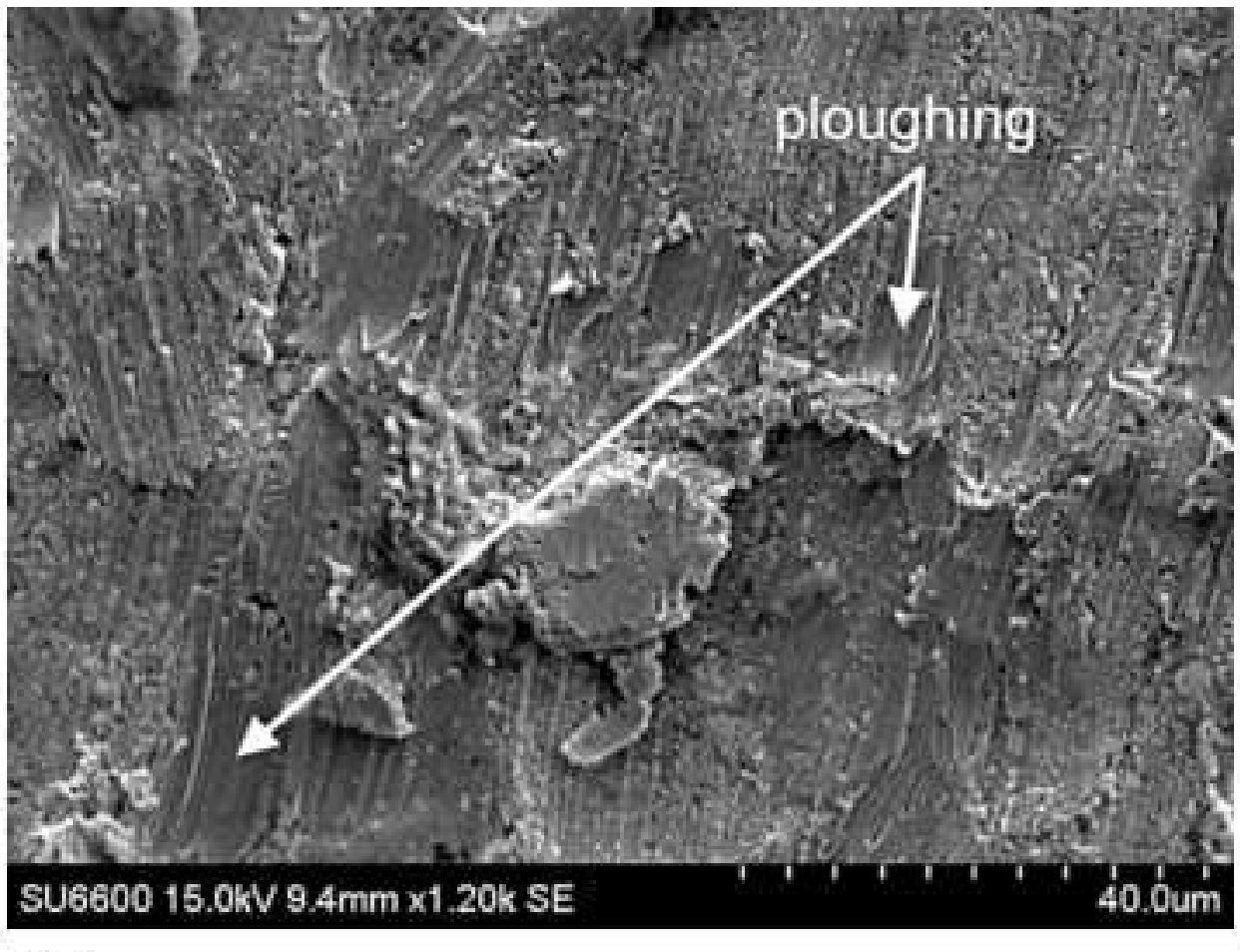

(a)

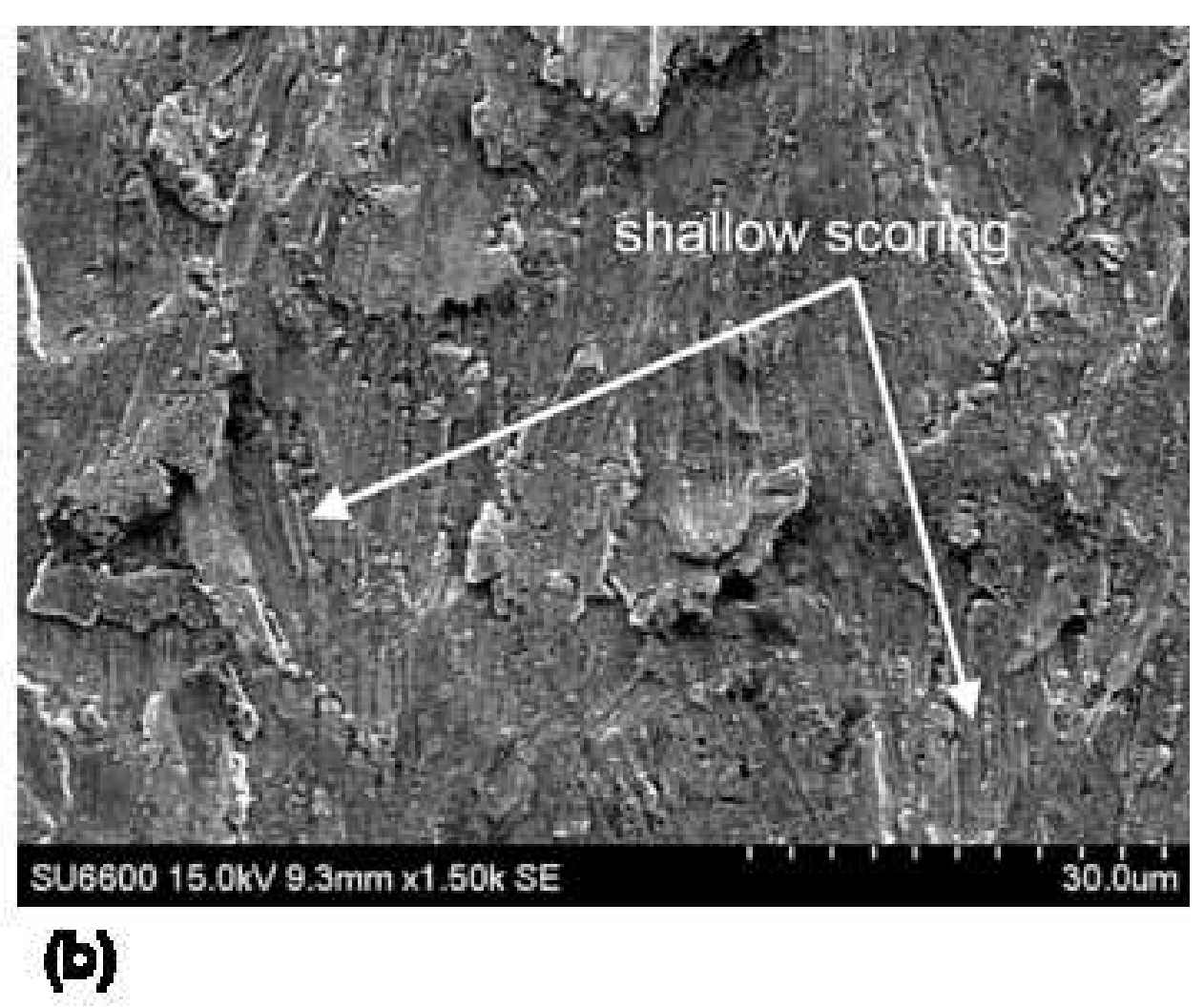

(b)

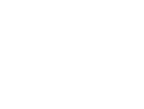


Click here to download high resolution image
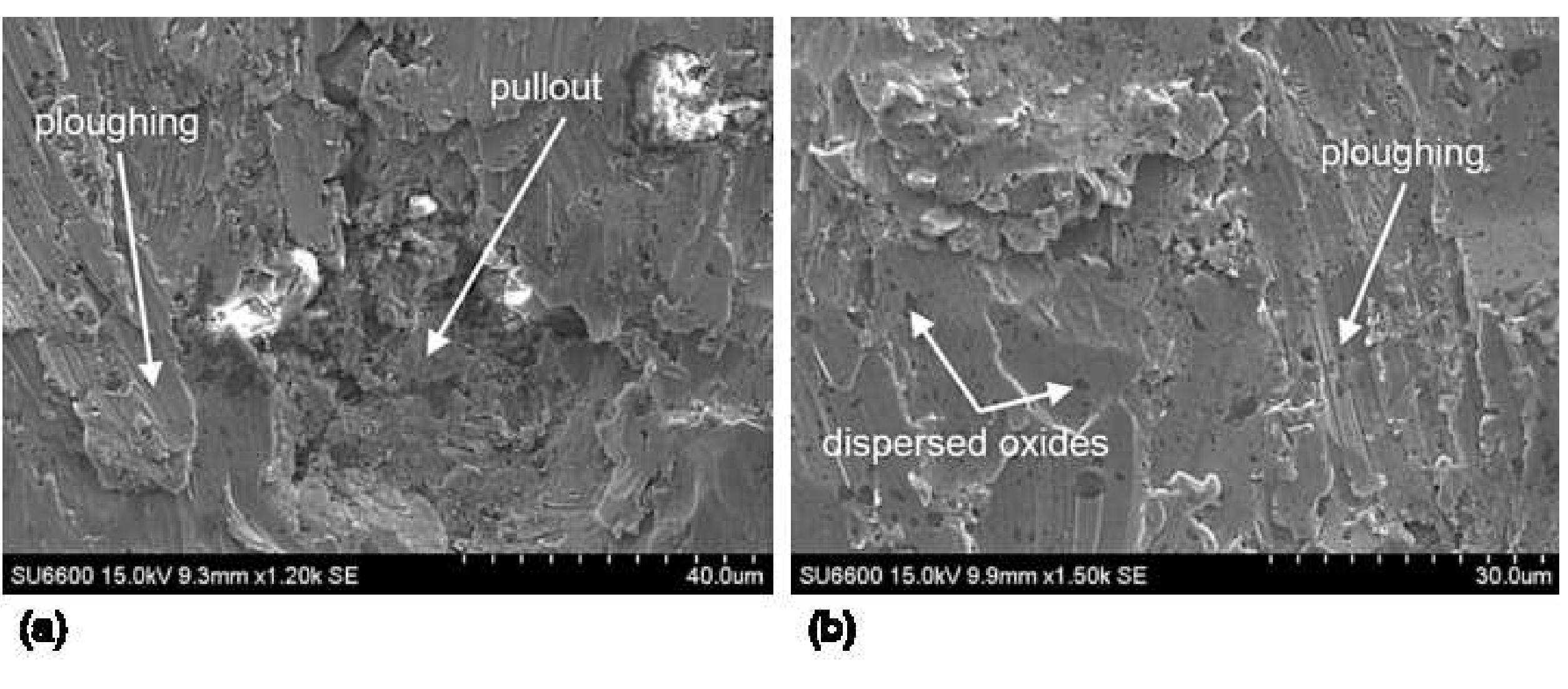

(a)

(b)

.
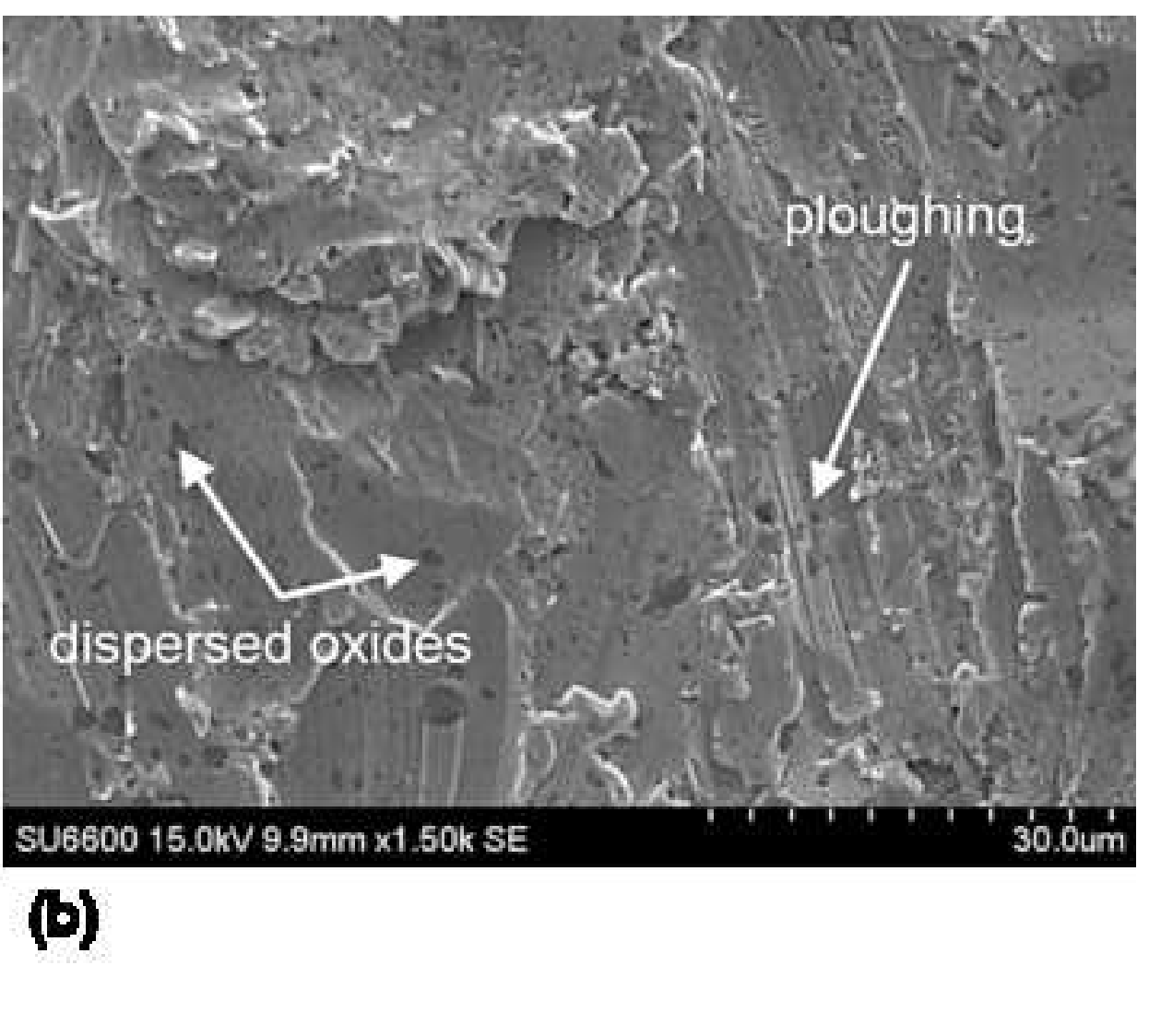